\title{
Las ciudades y sus muros de cristal. Ajuste neoliberal en una experiencia del noroeste argentino
}

\section{The cities and their glass walls; Neoliberal adjustment in an experience in northwestern Argentina}

\author{
LiLIANA BERGESIO* \\ LAURA GOLOVANEVSKY*
}

\begin{abstract}
In this article we discuss some consecquences of neoliberal policies in 1990's decade in Jujuy (Argentina), based on the study of changes that took place in the urban scenery of its capital city. Throughout the emergence and explosive development of a local district called Alto Comedero we observe how neoliberal policies deepened the division between social groups and relegating those less wealthy to remote and invisible parts of the city, leaving indelible marks on the imaginary, the subjectivities and the material life conditions of such groups.
\end{abstract}

Keywords: Cities, neoliberalism, Argentina northwest, society, urban districts.

\section{Resumen}

En este artículo se discuten algunas consecuencias de las políticas neoliberales de la década de 1990 en Jujuy (Argentina), a partir del estudio de los cambios en el entramado urbano de su capital. Con el surgimiento y desarrollo explosivo del barrio Alto Comedero se observa cómo las políticas neoliberales profundizaron la separación entre sectores sociales, generando procesos de relegación de grupos desfavorecidos a zonas alejadas e invisibles de la ciudad, dejando marcas indelebles en el imaginario, las subjetividades y las condiciones materiales de vida de tales grupos.

Palabras clave: Ciudades, neoliberalismo, noroeste argentino, sociedad, barrios urbanos.

\footnotetext{
*Universidad Nacional de Jujuy, correo-e: lilianabergesio@gmail.com, lauragolo@arnet.com.ar
} 


\section{Introducción}

Las políticas de ajuste de corte neoliberal aplicadas en Argentina y en el resto de América Latina en el último cuarto del siglo xx implicaron una reestructuración de la economía, cuyas consecuencias afectaron en diversos planos la vida de la población. El mercado de trabajo, el acceso a los sistemas de educación y salud y los niveles de pobreza fueron algunos de los aspectos involucrados; asimismo este ajuste implicó profundos cambios en el espacio urbano. Estudiándolos, pretendemos lograr una mejor comprensión de algunos de los resultados de las políticas neoliberales en una ciudad intermedia del noroeste argentino, San Salvador de Jujuy.

Nuestro punto de partida implica aceptar que las ciudades y su entorno urbano no son sólo una dimensión física, sino que constituyen, fundamentalmente, el espacio social que contiene las diversas experiencias de quienes habitan en él, con sus múltiples y cambiantes relaciones. Ellas concentran, en sus difusos y porosos límites, procesos de unión y separación, de dominio y subalternidad, de negociación y disputa. Facilitan la emergencia de nuevas formas de interacción, diálogo, convivencia, pero también de conflicto o ruptura, es decir, si bien conforman el escenario en el cual se llevan a cabo las prácticas sociales, las ciudades son mucho más que un mero telón de fondo, son el espacio significante donde se desarrollan las diferencias, los conflictos y los acuerdos entre grupos sociales, en su búsqueda de legitimar cada uno su propia definición acerca del sentido social de la vida (Reguillo, 1995).

Para el caso de las ciudades en América Latina, ellas tuvieron desde el comienzo de la colonización una gran relevancia como vigorosos centros de concentración del poder, asegurando la presencia de la cultura europea, dirigiendo el proceso económico y, sobre todo, trazando el perfil de las regiones sobre las que ejercían su influencia y, en conjunto, sobre toda el área latinoamericana. Es por ello que, si se persiguen las claves para la comprensión de los procesos latinoamericanos (pasados y presentes), es en las ciudades donde hay que buscarlas, "puesto que el mundo rural fue el que se mantuvo más estable y las ciudades fueron las que desencadenaron los cambios partiendo tanto de los impactos externos que recibieron como de las ideologías que elaboraron con elementos propios y extraños" (Romero, 2001: 9).

En épocas recientes, y sobre todo en las últimas cuatro décadas, los territorios se han alterado a la luz de los cambios económicos, tecnológicos y culturales. Vivimos en el tiempo de la revolución urbana (Lefebvre, 1972). Nuestro mundo es el de una urbanización generalizada, donde la mundialización de la economía y la globalización de las comunicaciones alteran las condiciones de vida y rompen los antiguos aparentes equilibrios 
que caracterizaban a muchas sociedades. Es así que el desarrollo de un nuevo sistema tecnológico unido a la desarticulación del estado de bienestar dio lugar a un proceso de reestructuración productiva a escala planetaria, configurando una nueva fase de modernización capitalista, en cuyo recorrido "tanto la morfología, la organización y el funcionamiento, como la propia apariencia de las ciudades que se habían venido definiendo desde el comienzo de la revolución industrial están siendo objeto de una radical mutación" (Mattos, 2006: 41).

Estas transformaciones recientes modificaron también la fisonomía de las ciudades latinoamericanas en general y de la República Argentina, en particular, donde las ciudades intermedias desempeñaron un nuevo rol como receptoras de población de diversos orígenes, desarrollándose procesos de fragmentación social que llegaron a su apogeo en la década de 1990. Es en este periodo que las propuestas de ciudad pierden ambigüedad, ya que la voluntad de integración (muchas veces presente en el discurso político, pero nunca alcanzada en los hechos) se desdibuja frente a tendencias claramente excluyentes (Bergesio et al., 2008). Así, las transformaciones resultantes de las políticas neoliberales parecen tender a la profundización de las desigualdades históricas (Valdés, 2009).

La ampliación de las brechas sociales ya existentes en la periferia ha dado lugar a numerosos debates, esto conlleva a dinámicas que modifican las fronteras internas de la ciudad y las relaciones entre territorios urbanos. En Argentina, la espacialización de las nuevas formas de pobreza urbana ha sido poco estudiada, como si nos hubiésemos quedado en la ecuación simple del pasado: villa miseria $^{1}=$ pobreza $=$ ilegalidad. Sin embargo, la observación de la ampliación de las formas de pobreza en la ciudad muestra que la dilución de la pobreza, por el contrario, no significa uniformización (Prévôt-Schapira, 2002).

Dentro de la relativa escasez de estudios en Argentina que den cuenta de cómo la pobreza urbana se refleja en el espacio de la ciudad, los mismos se han enfocado usualmente en el análisis de las grandes urbes, con especial énfasis en el área metropolitana de Buenos Aires. Las ciudades del interior, especialmente las pequeñas y medianas, parecen haber quedado fuera del interés mayoritario, por lo que en general sólo fueron objeto de estudios locales o regionales. ${ }^{2}$ Más aún, en muchos casos la separación

\footnotetext{
${ }^{1}$ En Argentina a las barriadas populares más pobres, a mediados del siglo xx, el "pueblo las fue bautizando individualmente con matices irónicos: Villa Tranquila, Villa Piolín, Villa Jardín, Villa Insuperable. Un periodista, Bernardo Verbitsky, las unificó como 'villas miseria', vocablo de singular fortuna. Polemizó, inclusive, reclamando la paternidad del nombre, pero ya no le pertenece" (Ratier, 1985:10). La cita precedente se refiere a la novela de Bernardo Verbitsky "Villa Miseria también es América”, cuya primer edición es de 1957.

${ }^{2}$ Véase, por ejemplo: Mignone (2005); Natera Rivas (1998); Malizia y Paolasso (2007); Olivera (2005); Schmidt (2004); Michelini y Davies (2009).
} 
dentro de las ciudades ha sido estudiada con enfoque en los barrios cerrados en los que se refugiaron grupos de alto poder adquisitivo.

Por ello, el presente artículo se detiene en el estudio del impacto de las políticas neoliberales en el proceso de urbanización de una ciudad de tamaño intermedio del interior de la República Argentina (San Salvador de Jujuy, capital de la provincia de Jujuy, en el extremo noroeste del país) en la década de 1990. Para ello el estudio se enfoca en la organización espacial del territorio de la ciudad, considerando al espacio como una vía para tratar de comprender la dinámica más amplia de los hechos sociales, enfatizando el rol de los barrios populares en este proceso.

La hipótesis de partida es que la implementación de las políticas neoliberales en Argentina de la década de 1990 agudizó la fragmentación social de las ciudades. En el caso de San Salvador de Jujuy, el surgimiento a partir de 1986 del barrio Alto Comedero, ubicado al sur de la ciudad, habitado por casi una quinta parte de la población de la capital provincial, ${ }^{3}$ refleja de manera paradigmática las consecuencias sociales de las políticas neoliberales implementadas con la convertibilidad en el espacio urbano de la capital jujeña.

En la presente investigación se desarrolla, en primer lugar, una revisión en torno a los conceptos de fragmentación, segregación y gueto con la finalidad de emitir, a través de ellos, una explicación del fenómeno que se observa en la ciudad de San Salvador de Jujuy; luego, se analizan brevemente los cambios descritos en las ciudades latinoamericanas durante el periodo de aplicación de las políticas de corte neoliberal. En tercer lugar, se especifica el por qué se considera a San Salvador de Jujuy como una ciudad intermedia, describiéndose además las principales características y algunos aspectos de la historia de la provincia de Jujuy y de su ciudad capital. En cuarto lugar, se trabaja con el barrio Alto Comedero como lugar clave para la comprensión de la historia reciente de la organización socio-espacial del entramado urbano. ${ }^{4}$ Finalmente, se discuten los cambios acaecidos en San Salvador de Jujuy y su interpretación en términos de fragmentación, segregación y gueto, en el marco de los procesos de exclusión social en Argentina de los últimos veinte años.

\footnotetext{
${ }^{3}$ Según datos del Censo Nacional de Población, Hogares y Vivienda (Indec, 2001).

${ }^{4}$ Para ello se expondrá de manera sintética, en un primer momento, una recopilación de información, con base en fuentes secundarias (revisión bibliográfica y hemerográfica), entrevistas no estructuradas y observaciones etnográficas acerca del origen, desarrollo y situación reciente del barrio Alto Comedero, enfatizando los aspectos socioeconómicos y demográficos. Esta primera etapa, fundamentalmente descriptiva, se completa con los datos obtenidos por este equipo de investigación mediante distintas estrategias metodológicas. En primer lugar, se realizaron una serie de entrevistas en profundidad a algunos dirigentes vecinales y funcionarios del barrio; en segundo lugar, se llevó a cabo una encuesta en noviembre de 2004 a habitantes del mismo. Estas dos instancias fueron complementadas, a su vez, con nuevas observaciones etnográficas y entrevistas no estructuradas.
} 


\section{Ciudad neoliberal: Fragmentación, segregación y guetos}

Los cambios sufridos por las ciudades de América Latina en las últimas décadas del siglo xx han sido estudiados desde las ciencias sociales recurriendo a diversos conceptos. Para el caso que nos ocupa, tres de ellos parecen mostrar un importante caudal de posibilidades analíticas, si se concreta el esfuerzo de diferenciar las situaciones que están caracterizando. Los términos de referencias son: segregación, fragmentación y gueto.

Con respecto al primero de estos conceptos, se puede distinguir entre aglomeración (clustering) y segregación (segregation). Mientras la primera alude a una reunión de un grupo poblacional en el espacio, la segunda se refiere a un proceso por el cual un grupo poblacional es forzado, involuntariamente, a aglomerarse en un área espacial definida. Sin embargo, otras definiciones se contraponen a ésta, negando la existencia de una relación directa entre desigualdades y segregación, reconociendo la posibilidad de que la segregación puede tener características tanto negativas como positivas, dejando el énfasis del concepto en su dimensión meramente espacial (Link, 2008). ${ }^{5}$

Rodríguez y Arriagada (2004) señalan que la segregación residencial se refiere a las formas en que los grupos de población se distribuyen de manera desigual en el territorio. Sabatini et al, (2001: 27) define a la segregación residencial como "el grado de proximidad espacial o de aglomeración territorial de las familias pertenecientes a un mismo grupo social, sea que éste se defina en términos étnicos, etarios, de preferencias religiosas o socioeconómicos, entre otras posibilidades". Este tipo de segregación se vincula de manera directa con la vida en las ciudades, por lo que no debería ser una cuestión novedosa. Pero en la actualidad pareciera haberse vuelto más visible y preocupante, debido al origen socioeconómico de la segregación residencial. Más aún, esta separación tiene una gran fuerza reproductora de las desigualdades, además de ser en sí misma una muestra de ellas.

Cuando los grupos más desfavorecidos conviven en zonas separadas del resto de la sociedad ven reducidas sus posibilidades de intercambio con otros grupos sociales, lo cual actúa limitando sus posibilidades de

\footnotetext{
${ }^{5}$ La noción de segregación que se trabaja en este artículo se refiere a la involuntaria (por falta de otras opciones) y no a la voluntaria (un grupo opta por separarse en un sector de la ciudad, siendo el ejemplo más típico los barrios privados). Esta última ha proliferado en las últimas décadas en América Latina y parece obedecer a varios motivos: por un lado, quienes optan por este tipo de residencia suelen sentirse atraídos por la percepción de seguridad o por un nuevo estilo de vida; por otro lado, los constructores y promotores inmobiliarios obtienen una significativa rentabilidad con la absorción a gran escala de elementos exógenos en estos proyectos de desarrollo altamente controlados. La complejidad que produce la combinación de ambas segregaciones escapa a los límites del presente trabajo, pero las dos son centrales para profundizar, como se esbozará en las conclusiones, en la relación entre segregación espacial urbana y diferencias sociales (Greenstein et al., 2000).
} 
ampliar su capital social y les impide compartir ciertos rasgos culturales que podrían colaborar para una movilidad social ascendente. La segregación residencial socioeconómica redunda también en segmentación educativa, dando lugar a circuitos educativos claramente diferenciados según el origen socioeconómico de los alumnos. Así, "los sistemas educativos, en un entorno de pobreza y desigualdad, en lugar de funcionar como vías de movilidad social y para la igualdad de oportunidades, se convierten en circuitos rígidamente segmentados para pobres y ricos, fomentando el 'círculo perverso' de la pobreza” (Golovanevsky, 2008: 244). La segmentación educativa y residencial condiciona la acumulación de capital social. Los menores, provenientes de hogares pobres, asisten a instituciones educativas en las que no pueden acceder por vía de los contactos a obtener mayor capital social, ni tampoco al capital simbólico que otorga el prestigio social. Al restringirse la interacción entre grupos socioeconómicos las brechas se profundizan. Más aún, la segregación residencial socioeconómica parece generar las condiciones para deteriorar "la vida comunitaria y la capacidad de acción colectiva, asociándose con la violencia y la desconfianza” (Rodríguez y Arriagada, 2004: 6).

En el caso de la noción de fragmentación también pueden señalarse distintas acepciones. Por un lado, una dimensión micro, donde el término se asocia a una ruptura, separación o distanciamiento social en la ciudad, derivado de fenómenos tales como el comportamiento del mercado de tierras, los emprendimientos inmobiliarios, los nuevos estilos de vida, la polarización social, la inseguridad creciente (todos ellos consecuencia de los cambios estructurales en la economía que han acentuado las diferencias sociales). En esta línea, las disparidades socioeconómicas, cada vez más marcadas, se traducen en una separación social en el espacio, de las cuales los barrios cerrados constituyen el símbolo por antonomasia. Por otro lado, una dimensión macro de la fragmentación, referida a un proceso más amplio de relocalización funcional de espacios en la ciudad, con el surgimiento de nuevos distritos urbanos que se vinculan a las novedosas formas de organización de la producción en la actual fase del capitalismo y a los recientes patrones culturales y de consumo. Esta concepción de fragmentación responde, entonces, a un doble proceso que amuralla áreas de la ciudad con la finalidad de proteger a ciertos sectores sociales (micro) y relocaliza otros espacios urbanos en el marco de los procesos de metropolización expandida, suburbanización y periurbanización (macro). Y si bien ambas dimensiones de la fragmentación aumentarían su valor explicativo si se considerasen de manera conjunta, en general en los estudios urbanos son tratadas por separado, sin indagar sobre la relación entre ambas (Link, 2008). 
En otra línea argumentativa se propone interpretar las reconfiguraciones urbanas con énfasis en las situaciones de relegación con base en la noción de gueto (Valdés, 2009). Los estudios clásicos que aluden a este concepto pueden atribuirse a Wacquant, quien desde una óptica de países desarrollados estudia el gueto afroamericano de la ciudad de Chicago en Estados Unidos (Wacquant, 2001), comparándolo también con un barrio de un suburbio industrial de París, la banlieu (Wacquant, 2007). Este autor desarrolla una concepción institucionalista del gueto "como concatenación de mecanismos de control etnorracial, fundada en la historia y materializada en la geografía de la ciudad" (Wacquant, 2007: 15), el cual se constituye así en "un instrumento socio-organizacional compuesto por cuatro elementos (el estigma, la restricción, el confinamiento espacial y el encasillamiento institucional) que emplea el espacio para reconciliar los dos propósitos antinómicos de la explotación económica y el ostracismo social" (Wacquant, 2004: 72). Gueto y banlieu son vistos como equivalentes de las villas de emergencia en Argentina (y de sus similares en el resto de América Latina) en cuanto que son "lugares estigmatizados y situados en lo más bajo del sistema jerárquico de los sitios que componen una metrópoli” (Wacquant, 2007: 13), aunque el concepto de gueto implica otros componentes que lo definen como tal (Valdés, 2009).

Pero el espacio urbano surge de relaciones entre las clases sociales, el Estado y la ciudad. Es por tanto una construcción histórica y política, por lo que para entender el barrio no se debe dejar de lado el marco más amplio de la ciudad que lo contiene, la región e inclusive el país, además de requerir de una mirada diacrónica. El barrio no hace más que mostrar diferencias socioeconómicas que se originan fuera de él (Wacquant, 2007). Un barrio determinado en una ciudad dada, sólo se entiende si se lo mira en relación con el resto de la ciudad y se considera, a su vez, el contexto más amplio (económico, político, social) en el cual ese barrio nace y se desarrolla. Porque la historia de la configuración socioespacial de las ciudades es producto de una particular interacción entre fuerzas macroestructurales, políticas estatales, y el compromiso activo de los habitantes del barrio (tanto en cuanto individuos como a través de sus organizaciones colectivas) con esas presiones externas (Bergesio et al., 2009b). Es así que los guetos urbanos, verdaderos enclaves de pobreza en las ciudades, no son el producto de la acción de una sola fuerza o actor (hiperurbanización, políticas habitacionales, entre otras posibles) sino de la "interrelación de actores en disputa y los constantes cambios en la estructura de oportunidades políticas -regímenes autoritarios y democráticos" (Auyero, 2001: 22-23). Así, el gueto "aparece como una institución contenedora y propia de un grupo social estigmatizado pero que, a la vez, es utilizado 
económicamente en condiciones de explotación. No se define, entonces, por su situación de segregación ni por riqueza ni por pobreza" (Valdés, 2009: 42).

Para América Latina, diferentes autores han utilizado el concepto de gueto definiéndolo como el sector residencial urbano donde habita una minoría separada del resto de la sociedad (Valdés, 2009). Katzman (2001) considera que la conformación de los guetos de la pobreza se origina en los procesos de desindustrialización y desestatización que caracterizaron a las economías latinoamericanas desde la década de 1980. Carlos (1997) habla de guetos en relación con los condominios cerrados de la periferia urbana. Para estos autores los guetos concentran la población que sufre la marginalidad con respecto a la sociedad total, implicando así a los conceptos tanto de segregación como de fragmentación. Pero también, "a la estigmatización, en tanto se refiere a condiciones objetivas de localización, permanencia y transitabilidad para 'otras clases sociales' (en sentido Bourdiano) y reconoce su base territorial en una porción del territorio urbano y en la lucha por la apropiación de los recursos urbanos" (Valdés, 2009: 43).

Segmentación, fragmentación y gueto son los conceptos que logran acercar una explicación para el caso que interesa en este escrito. Pero esos procesos no son naturales sino históricos y fueron generados por un modelo económico: el neoliberal.

\section{Las ciudades latinoamericanas bajo el signo neoliberal}

En la República Argentina, durante la mayor parte del siglo xx, la sociedad se distinguió de la de otros países periféricos por sus amplias capas medias y su estructura social relativamente más igualitaria. Desde el último golpe de Estado, en 1976, el país experimentó una significativa transformación vinculada al abandono del modelo de industrialización por sustitución de importaciones (ISI) y a la adopción del modelo neoliberal, que llegó a su máxima expresión en la década de 1990.

En la etapa IsI, el crecimiento de la mayoría de las ciudades de América Latina no produjo una clara segregación espacial. Durante el periodo de rápido crecimiento de las ciudades latinoamericanas en las décadas de 1960 y 1970, los recién llegados no ganaban lo suficiente como para formar un mercado para el sector inmobiliario (estatal o privado). Por el contrario, los pobladores construyeron sus viviendas con sus propias manos, donde pudieron ocupar, incluso, terrenos de forma ilegal o semilegal. En este proceso edificaron, literalmente, la periferia de la ciudad. Este crecimiento desordenado de las ciudades latinoamericanas generó múltiples trabas para las familias de medianos y altos ingresos e impidió 
una suburbanización a gran escala. En muchas de estas ciudades el Estado era el propietario de los terrenos dentro y alrededor de las ciudades, lo cual no sólo limitó el mercado de terrenos sino que lo hizo fácil blanco de las invasiones. El resultado fue un patrón de segregación residencial en donde los sectores de bajos ingresos estaban cerca de las clases pudientes. Es cierto que los ricos se mantenían relativamente aislados en barrios de casas grandes y departamentos de lujo, pero su número fue demasiado pequeño para segregarse en gran escala de las otras clases. Las invasiones de tierras de las poblaciones de bajos y medianos recursos compensaban las tendencias de dispersión y segregación espacial por clase social. En tiempos de crisis económica, los sectores de ingresos medios buscaron viviendas más baratas en barrios pobres. Mientras tanto la elite, buscando un mayor espacio y un ambiente más saludable, fue construyendo un sector de la ciudad que en su forma espacial pura se asemejaba a un cono, empezando en el centro de la ciudad y terminando en la periferia. El ordenamiento territorial durante la década de 1970 no se basó en una inversión del Estado sino en una economía de pleno empleo, que proveía a la clase trabajadora del ingreso necesario para comprar terrenos y mejorar sus viviendas. En la década de 1970 las áreas más homogéneas en términos sociales eran las periféricas, donde los sectores de bajos recursos invadieron o compraron terrenos baratos y construyeron sus viviendas. La heterogeneidad social y la pobreza de la mayoría de los habitantes de las ciudades contribuyeron a que estos se vieran a sí mismos compartiendo una situación habitacional común, pese a tener diversas ocupaciones y posiciones de clase objetivamente distintas (Roberts y Portes, 2005).

En América Latina los primeros ensayos de aplicación de políticas neoliberales se desarrollaron en Chile a partir de 1972 y en Bolivia a partir de 1985. Pero, el verdadero clima neoliberal en esta región del mundo, encuadrado en el Consenso de Washington y en la recuperación de sistemas democráticos formales -superadores de los gobiernos y regímenes militares anteriores- se inició hacia fines de la década de 1980 y comienzos de la de 1990. En una apretada síntesis se puede afirmar que el modelo neoliberal implementado en varios países de América Latina, y en especial en la República Argentina, en la década de 1990, se caracterizó por una desregulación amplia y apertura asimétrica de la economía, el desmantelamiento del sector público y la autonomía del sector financiero respecto de la producción y el comercio. En este esquema general el Estado abandonó sus funciones de promoción e integración social y reorientó su acción, contribuyendo a la definición de ganadores y perdedores a través de una firme intervención en la fijación del tipo de cambio, tasas de interés y política tributaria, bombeando ingresos en beneficio del sector financiero globalizado (Bergesio y Fandos, 2009c). 
Ahora bien, ¿cómo afectó este modelo económico a la estructura socioespacial de las ciudades latinoamericanas? Portes y Roberts (2005) examinan la evolución de las ciudades de América Latina durante las dos últimas décadas del siglo xx y los primeros años del siglo xxi con base en datos comparables de seis países (entre ellos Argentina) que abarcan conjuntamente más de $80 \%$ de la población de la región. Allí llegan a la conclusión de que algo significativo ha cambiado en las ciudades latinoamericanas y en el carácter de su vida cotidiana. Primero, la tradicional primacía urbana ha disminuido en casi todas partes, dando paso a un rápido crecimiento de centros secundarios y a un sistema urbano complejo, cuya futura evolución aún permanece incierta. La relativa disminución de la tradicional primacía se ha debido, entre otros factores, a la pérdida de la atracción que, en otra época, ejerció la gran ciudad sobre los migrantes, internos e internacionales; a la caída de los niveles de fertilidad de estos grupos, y a la atracción económica de los nuevos polos de crecimiento generados por el nuevo modelo exportador. Segundo, los mercados laborales también han sido fuertemente afectados por la discriminación del empleo industrial formal debido a la bancarrota de industrias anteriormente protegidas por el modelo sustitutivo y la contracción del empleo público, con un significativo aumento del desempleo abierto en algunos países y una contracción del crecimiento del empleo formal. Tercero, la pobreza y la desigualdad siguieron una tendencia paralela. Aunque la pobreza no se incrementó de la misma manera en todas partes, la tendencia común para todos los países fue la persistencia de los niveles de desigualdad. El proletariado informal es la clase social que más crece durante el periodo de ajuste neoliberal, mientras que el estancamiento o disminución del salario real promedio durante el mismo periodo mantuvo a las clases trabajadoras, con la excepción de Chile, en los umbrales de la pobreza. Cuarto, la delincuencia se incrementó (especialmente el asalto y el hurto), lo que puede ser visto como la contracara de la falta de oportunidades en el mercado laboral y de los crecientes niveles de desigualdad. Este fenómeno se presenta en todos los países latinoamericanos y en todas sus principales ciudades, abarcando no sólo las áreas pobres de las mismas, sino también las habitadas por los grupos más favorecidos. Esta última situación ha llevado, entre otras consecuencias, a la proliferación de comunidades cerradas para salvaguardar la riqueza, y a un incremento exponencial de la seguridad privada. Todo esto fue modificando la fisonomía de las ciudades y las construcciones simbólicas del territorio, procesos que encuentran su explicación en las nociones de 
segregación, fragmentación, guetos urbanos (voluntarios e involuntarios), ${ }^{6}$ ya desarrollados en este escrito.

En Argentina son numerosos los estudios que analizan las transformaciones en el espacio urbano para el área metropolitana de Buenos Aires. ${ }^{7}$ La mayoría de ellos coinciden en señalar la acentuación de los procesos de segregación espacial como uno de los rasgos clave. La desocupación y la precarización laboral de una porción importante de la población, con la consiguiente pérdida de ingresos o inestabilidad de los mismos, refuerzan la marginación de los grupos más pobres, que se expresa también en términos espaciales (Prévôt, 2002). A la par de la proliferación de complejos habitacionales lujosos, country clubs y barrios cerrados, se ha reducido el tránsito entre sectores sociales. Los dormitorios obreros se han convertido en espacios de desempleados, de aquellos que han sido expulsados del sistema social. "El neoliberalismo ha profundizado cualitativamente las antiguas fronteras urbanas de Buenos Aires, transformando a muchos barrios populares en guetos sociales, en instituciones totales de la miseria" (Cerrutti y Grimson, 2005: 136). La dicotomía, como en otros modelos neoliberales, dejó de ser arriba/abajo para pasar a ser adentro/ afuera, quienes ganaron con el modelo están adentro (Svampa, 2001) y los que perdieron, afuera.

La confluencia de tendencias de carácter mundial, políticas nacionales y locales, dieron lugar al desarrollo del sector inmobiliario en estrecho vínculo con las nuevas formas de consumo y de esparcimiento. La transformación de Puerto Madero, la aparición de los shoppings (a fines de la década de 1980), la instalación de las grandes cadenas hoteleras internacionales, fueron todas, grandes operaciones que terminaron profundizando los ya existentes contrastes entre el norte y el sur de la ciudad, entre la capital y los suburbios, entre la primera y la segunda coronas del conurbano. Esto se refleja también en la ampliación de las brechas entre los indicadores de ingresos, salud y mortalidad infantil entre dichos sectores de la ciudad (Prévôt, 2002).

Como saldo de las políticas neoliberales del último cuarto del siglo xx en Argentina, puede señalarse que si bien el Estado cambió sustancialmente su presencia, lejos está hoy de haber desaparecido, e incluso tiene en la actualidad una enorme importancia en la vida cotidiana y en la

\footnotetext{
6 'Cercarse en 'una comunidad cerrada' no puede sino significar también excluir a todos los demás de los lugares dignos, agradables y seguros, y encerrarlos en sus barrios pobres. En las grandes ciudades, el espacio se divide en 'comunidades cerradas' (guetos voluntarios) y 'barrios miserables' (guetos involuntarios). El resto de la población lleva una incómoda existencia entre esos dos extremos, sońando con acceder a los guetos voluntarios y temiendo caer en los involuntarios", en entrevista a Zygmunt Bauman: "El estado benefactor volvió para los ricos", Revista Ñ, 18 de julio de 2009, p. 7.

${ }^{7}$ En este trabajo citamos sólo algunos de ellos, porque enfatizan rasgos que consideramos necesario destacar en función de los objetivos del presente artículo.
} 
subsistencia de una importante porción de la población. Aunque parezca paradójico, el proceso de desregulación de la economía y el intento de reducir el rol del Estado ha generado consecuencias tales que el propio sector público ha tenido que hacerse cargo en parte de las numerosas víctimas que tales políticas generaron; es decir, intentar reducir el Estado y tergiversar sus funciones "parece terminar generando una serie de problemas más graves que debe resolver finalmente el propio Estado" (Bergesio et al., 2009a: 240). Un reflejo de esto podría ser el caso del barrio Alto Comedero, en la ciudad de San Salvador de Jujuy.

Por eso, nos preguntamos, ¿qué sucedió en la década de 1990 en una ciudad intermedia de Argentina? ¿Sigue el patrón de las grandes metrópolis o presenta una estructuración socioespacial diferente?

\section{Una ciudad intermedia en el noroeste argentino: San Salvador de Jujuy}

Las grandes transformaciones ocurridas en los centros urbanos en las últimas décadas han sido poco estudiadas, específicamente el caso de las ciudades intermedias tanto en América Latina, como en Argentina. Sin embargo, ellas son ejemplo de la fragmentación socio-espacial y funcional, que se expresa en la generación de novedosos bloques en el entramado urbano, por ejemplo, la edificación de barrios cerrados, grandes centros comerciales y parques industriales, dando lugar a un nuevo modelo estructural de las ciudades intermedias (Borsdorf et al., 2008).

Pero, ¿a qué llamamos ciudades intermedias? ¿’Por qué decimos que San Salvador de Jujuy es una ciudad intermedia? Si bien no existe una definición común y generalmente aceptada, pueden identificarse tres elementos centrales: "el contexto del sistema urbano nacional, el número de habitantes y la relación de funciones que éstas cumplen" (Borsdorf et al., 2008: 2). Dependiendo del país de que se trate, una ciudad con una cierta cantidad de habitantes puede ser grande para un país, intermedia o pequeña para otro. Uno de los rasgos que caracteriza a las ciudades intermedias es precisamente su capacidad de intermediar entre ciudades de mayor concentración urbana y espacios rurales colindantes (Mertins, 1995; Bellet-Sanfeliu y Llop, 2004). En general, al no existir una definición clara (la que por otra parte tampoco parece fácil de lograr), los límites son establecidos arbitrariamente por los diferentes autores. Para Argentina, Vapñarsky (1994) establece en cincuenta mil habitantes el mínimo para una aglomeración de tamaño intermedio (exceptuando a las localidades del Gran Buenos Aires).

\footnotetext{
${ }^{8}$ Se agradecen los aportes de Alejandra del Castillo en este punto.
} 
En este marco, consideramos a San Salvador de Jujuy como una ciudad intermedia por su peso en la población de la provincia: con 231,229 habitantes. ${ }^{9}$ En ella reside $37.8 \%$ de la población de Jujuy, formando junto con las vecinas localidades de Palpalá y Yala un aglomerado (Gran San Salvador de Jujuy) de 278,336 habitantes (45.5\% de la población provincial). Además, por ser la ciudad capital de la provincia, en ella se concentran los servicios que en localidades más pequeñas no se pueden encontrar, tales como los de salud de mayor complejidad; los servicios de educación más sofisticados; las actividades bancarias y financieras en su mayoría e inclusive las delegaciones tributarias de orden nacional. ${ }^{10} \mathrm{~A}$ nivel del país, su tamaño la ubica en el grupo intermedio de las capitales de provincia, siendo superada en población por 10 capitales de provincia, 16 de los 24 partidos del conurbano bonaerense y las ciudades de Rosario y Mar del Plata; es decir, tanto en términos de cantidad de habitantes, como de las funciones que cumple a nivel provincial y en función del contexto del sistema urbano nacional, evaluamos que puede considerarse a San Salvador de Jujuy como una ciudad intermedia dentro de la República Argentina.

Como consecuencia de la reestructuración productiva y la disminución de las migraciones internas hacia las grandes urbes, desde mediados de la década de 1970 la primacía del Gran Buenos Aires ha comenzado a disminuir, redireccionándose las migraciones y el crecimiento hacia las ciudades intermedias del interior de Argentina (Vapñarsky, 1994). En este proceso también ha colaborado la crisis de las economías regionales, expulsando mano de obra de actividades propias de áreas rurales, lo que generó migraciones intraprovinciales hacia ciudades principales dentro de cada provincia, pero intermedias en términos de su peso en el conjunto del país. Es así que, hasta fines de la década de 1960, la gran mayoría de los flujos migratorios tenía como destino el Gran Buenos Aires (en 1970, 60\% de los migrantes internos residía en ese aglomerado) y su origen cubría prácticamente todo el país, a los que se le sumaban los que habían nacido en el extranjero, sobre todo en los países limítrofes. Pero luego el panorama cambió y el Gran Buenos Aires atrajo poca migración (por ejemplo, en 1991 se registraron 400,000 migrantes menos que en 1980) o por lo menos "se establece un balance entre inmigrantes y migrantes, y son las ciudades medianas y medianas-grandes las que ejercen ahora un fuerte poder de atracción" (Reboratti, 1995: 203). En muchos casos estas últimas aglomeraciones no tenían la suficiente capacidad como para recibir a las familias procedentes de otras zonas de la provincia, lo

${ }^{9}$ Censo Nacional de Población, Hogares y Vivienda (INDEC, 2001).

${ }^{10}$ Más aún, no hay cines que integren el circuito comercial en la provincia, fuera de los de San Salvador de Jujuy. 
que dio lugar a que se instalaran en asentamientos y barrios marginales, en la periferia de estas ciudades, generando insuficiencia de los servicios públicos: educación, salud, seguridad y transporte, entre otros. En este sentido, el caso del barrio Alto Comedero en San Salvador de Jujuy (que presentaremos más adelante a detalle) resulta paradigmático.

\subsection{La provincia de Jujuy}

La provincia de Jujuy se ubica en el extremo noroeste de la República Argentina (ver mapa I y II). Limita al norte con Bolivia, al oeste con Chile y al sur y al este con la provincia de Salta. Conforma con las provincias de Salta, Tucumán, Santiago del Estero y Catamarca la región del noroeste argentino (NOA). ${ }^{11}$ Esta región tiene una larga historia con fronteras difusas y un tanto porosas, marcada por la diversidad étnica y de formas de ocupación del espacio. Los patrones culturales, la organización social y la historia compartida la enmarcan en el sur de la región ${ }^{12}$ andina latinoamericana (Bergesio, 2000).

Jujuy se caracteriza por tener una amplia variedad de climas y diversidad ecológica. Usualmente, se la estudia con base en cuatro zonas (mapa III) denominadas Valles (donde se encuentra la ciudad capital, la industria siderúrgica de la exempresa estatal Altos Hornos Zapla y las plantaciones de tabaco), Ramal (que abarca las zonas azucareras y frutihortícolas), Quebrada y Puna (ambas zonas de esplendor en la época colonial, por ser pasaje hacia el Alto Perú, hoy empobrecidas y despobladas). Los movimientos de población a lo largo de un siglo y medio, aproximadamente (según la evolución de los censos de población entre 1866 y 2001), llevan a concluir que el crecimiento poblacional acompaña al desarrollo económico de las diferentes regiones (Bergesio et al., 2009b).

En todo el periodo que va desde la época colonial hasta la actualidad hubo un fuerte proceso de urbanización en la provincia de Jujuy. Dado que no hubo un crecimiento industrial capaz de absorber el importante aumento de la fuerza de trabajo urbana, gran parte de la población procedente de zonas rurales se incorporó al sector terciario de la economía, asentándose especialmente en la región de los valles bajos, donde el pun-

\footnotetext{
${ }^{11}$ Algunas definiciones de la región NOA incluyen también a La Rioja (INDEC, 2001), aunque actualmente se la suele asociar a Mendoza, San Juan y San Luis en la denominada región Nuevo Cuyo.

${ }^{12}$ Para Barsky (2000) la región es histórica, es el lugar donde se territorializa la historia; es también la puesta en valor y producción del territorio, generando una visión cambiante y dinámica del espacio geográfico. Para este autor los componentes físicos desempeñan un papel importante en la medida que son componentes de una geografía construida históricamente. En este sentido, el escenario forma parte de la historia, pero los territorios son productos de la dominación ejercida por los hombres.
} 

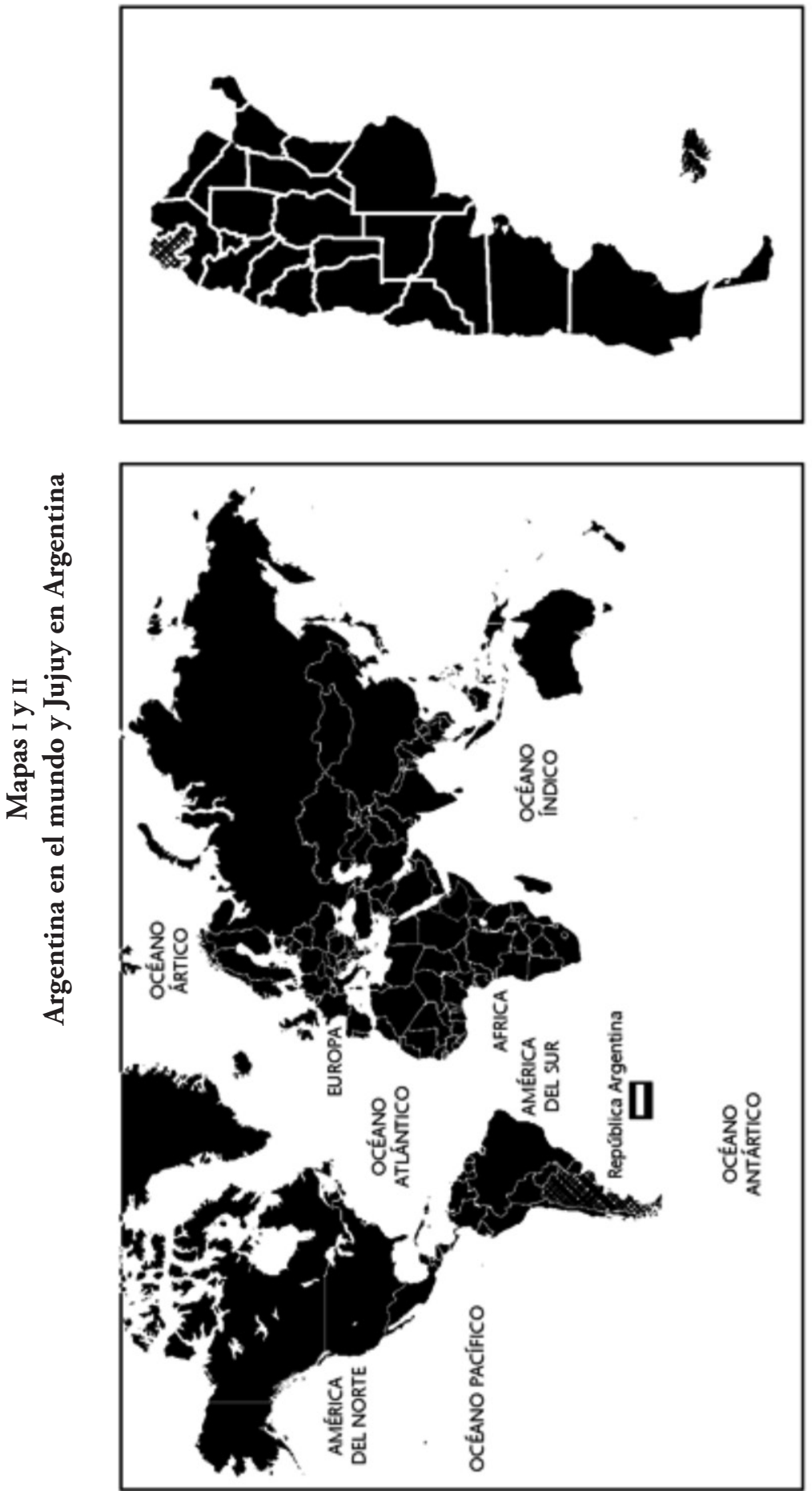

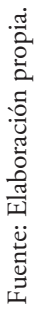




\section{Mapa III \\ La provincia de Jujuy, sus departamentos \\ y zonas ecológicas-productivas}

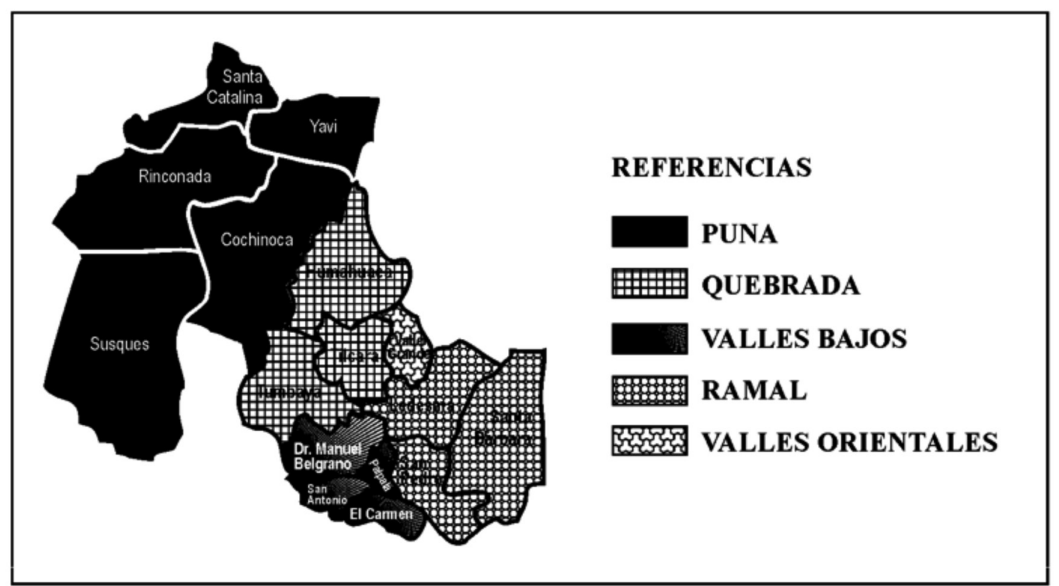

Fuente: Elaboración propia.

to urbano de mayor atracción fue siempre la ciudad capital: San Salvador de Jujuy.

En el resto de las regiones, mientras que la Puna perdía población, en buena medida por ser proveedora de mano de obra para las actividades vinculadas a la caña de azúcar, ${ }^{13}$ el Ramal detuvo, o desaceleró, su crecimiento. Cuando el requerimiento de mano de obra para la actividad cañera perdió importancia, dicha zona dejó de ser destino de migrantes provenientes de la Puna, quienes se dirigieron hacia los valles bajos. Esta región aumentó así su importancia relativa, no tanto debido al desarrollo de actividades productivas, sino más bien por el crecimiento de los servicios. Entonces, dado que la Puna (y también la región de la Quebrada de Humahuaca) seguía expulsando fuerza de trabajo, pero ésta no se dirigía ya hacia la zona azucarera, una consecuencia lógica fue que, quienes no migraban fuera de la provincia, se fueran incorporando al sector terciario, particularmente en San Salvador de Jujuy. La población se concentra así en la región de los valles bajos, especialmente en los departamentos Dr. Manuel Belgrano, Palpalá y El Carmen, que en 1991 representaban en conjunto $57.3 \%$ del total de la población de la provincia (que según el Censo Nacional de Población y Vivienda 2001 era de 61 1,888 habitantes). Al producirse una acelerada migración hacia la ciudad de San Salvador

\footnotetext{
${ }^{13}$ Con respecto de la complementariedad entre las necesidades de mano de obra estacional de los ingenios azucareros y el sistema de hacienda de la Puna puede verse el trabajo de Rutledge (1987).
} 
de Jujuy, se generó una importante demanda de viviendas y un notorio proceso de asentamiento en terrenos fiscales (Bergesio et al., 2009b).

\subsection{San Salvador de Jujuy: desde su fundación a la actualidad}

San Salvador de Jujuy fue fundada en 1593, entre los ríos Grande y Chico o Xibi Xibi, luego de dos intentos previos que habían fracasado, en 1557 y 1563 . A partir de su fundación definitiva los españoles organizaron la ciudad siguiendo el modelo de la cuadrícula en damero exacto (García-Vargas, 2003). ${ }^{14}$ Desde ese momento y hasta el presente, la ciudad tuvo un crecimiento demográfico coincidente con la ocupación de nuevas áreas destinadas a la vivienda.

Aunque desde su fundación y hasta fines del siglo XIX, el crecimiento de la ciudad fue paulatino pero constante, éste se limitó a un triángulo demarcado por el río Grande, el río Xibi Xibi y por el borde de la terraza de los Altos de Quintana (hoy límite entre los barrios Centro y Ciudad de Nieva). Pero entre los últimos ańos del siglo xIx y los primeros del $x x$ comenzaron a operarse algunos cambios en la fisonomía urbana que son el resultado de dos procesos paralelos. Por un lado, el aumento demográfico producido por la llegada de, en su mayoría, inmigrantes de países limítrofes, fundamentalmente de origen boliviano y, en menor medida, de ultramar (con una fuerte concentración de italianos). A esto se sumó una importante afluencia de migrantes rurales y de otras ciudades argentinas. Este aumento notable de la población urbana generó, como era de esperar, la ampliación y densificación del sector urbano de la ciudad, que incrementó su población de manera tal que hacia 1914 la población urbana del departamento Capital (hoy Dr. Manuel Belgrano) ya superaba a la rural (Delgado et al., 2006). ${ }^{15}$

Entre 1914 y 1935 la población de San Salvador de Jujuy se triplica y esto se evidencia en la urbanización de nuevas áreas. Entre 1935 y 1960 la ciudad continúa expandiéndose hacia el norte sobre la margen derecha del río Grande y hacia el sudoeste superando la barrera de los Altos de Quintana. En este periodo se expandieron varios servicios, tal vez siguiendo el ritmo de estado benefactor en auge, ${ }^{16}$ que fomentó el acceso a la

\footnotetext{
${ }^{14}$ La ciudad colonial hispanoamericana se caracterizaba por una fuerte centralización, un gradiente social centro-periferia y el principio de una estructuración socio-espacial en círculos (Borsdorf, 2003), lo que se reprodujo en San Salvador de Jujuy.

${ }^{15}$ Para el caso de América Latina en general, en esta primera fase de rápida urbanización -denominada por Borsdorf (2003) la ciudad sectorial- se quiebra la estructura circular que caracterizaba a la ciudad colonial. El centro, que era exclusivamente administrativo en la época colonial, pasa a ser también centro comercial, y crecen los barrios altos (Borsdorf, 2003).

${ }^{16}$ Aunque en Argentina, al igual que en el resto de América Latina, el estado de bienestar tuvo un carácter embrionario y nunca llegó a desarrollarse plenamente, como sí lo hizo en Europa (Marshall, 1988).
} 
vivienda propia y el desarrollo de una amplia infraestructura sanitaria y educativa. Esto se reflejó en la constante inversión en rubros como pavimentación, alumbrado, aguas corrientes, servicios urbanos de pasajeros, entre otros.

Otro proceso de transformación urbana fue el avance de construcciones verticales que paulatinamente fueron modificando el paisaje urbano. Desde su fundación hasta la década de 1970 la ciudad había seguido un desarrollo no planificado desde el Estado. ${ }^{17}$ Se ocupaban generalmente las tierras que eran vendidas por sus dueños, y los particulares que las compraban llevaban a cabo la construcción de las viviendas. Pero también se dio el caso de urbanizaciones populares que ocupaban tierras fiscales o privadas - por lo común en zonas ampliamente visibles- y luego de un largo proceso, generalmente vinculado con la autoorganización de los vecinos, obtenían la tenencia de la tierra. En este último caso son los sectores populares los protagonistas activos del crecimiento urbano. ${ }^{18}$

En 1977 se crea el Instituto de Vivienda y Urbanismo de Jujuy (IVUJ) en concordancia con el Fondo Nacional de la Vivienda (Fonavi). ${ }^{19}$ En este momento empieza una nueva etapa en la ocupación del espacio urbano, en la que el IVUj organiza planes quinquenales y trienales, en función de la demanda poblacional y de la disponibilidad de tierras fiscales o privadas pasibles de expropiación. En este momento el crecimiento de la ciudad se orienta siguiendo la dirección este-sudeste.

En 1978, un gobierno militar realiza por primera vez en Jujuy una relocalización masiva de personas instaladas en tierras fiscales. Las traslada a una zona al sudeste: El Arenal. "A fines de la década del ochenta, acentuando la tendencia hacia el sudeste, ${ }^{20}$ la ciudad continúa creciendo con la formación de una gigantesca urbanización a quince kilómetros del centro" (García-Moritán, 1997: 35). Esta urbanización es el barrio Alto

\footnotetext{
${ }^{17}$ En 1958 la Universidad Nacional de Tucumán (UNT) elabora un Plan de Ordenamiento Territorial y se elabora otro en 1970 por parte del Consejo Federal de Inversiones (CFI), aunque ninguno de ellos fue ejecutado.

${ }^{18}$ Todo este periodo (1920-1970), que puede ser considerado como la segunda fase de rápida urbanización, es denominado por Borsdorf (2003) la ciudad polarizada para el caso de las ciudades latinoamericanas. En ella los barrios de la clase baja y de grupos marginales se expandieron en el centro a través de estructuras en forma de pasaje (cité, casita, vecindad o conventillo). En esta misma época nacieron los barrios marginales periféricos (callampas, barriadas o villas miserias), localizados tanto en nichos no edificados dentro del perímetro urbano como en lotes aislados fuera de la ciudad. También fueron construidos barrios de vivienda social en la periferia urbana. Mientras tanto, los ricos se alejaban cada vez más del centro de la ciudad poblando barrios exclusivos. Así, se fue profundizando el contraste entre una ciudad rica y una ciudad pobre, dando lugar a una polarización fruto del crecimiento celular fuera del perímetro urbano. Importantes flujos migratorios se dirigieron a los conventillos centrales, y desde ahí hacia los barrios marginales periféricos. Estos flujos son considerados como ejemplos de la movilidad vertical hacia la vivienda social (Borsdorf, 2003).

${ }^{19}$ En 1993 el Fonavi desaparece y el IvUj, que dependía de éste, pasa a la provincia.

${ }^{20} \mathrm{El}$ resaltado es nuestro.
} 
Comedero: la nueva ciudad. ${ }^{21}$ Pero antes de describir este caso en particular es importante presentar un panorama de la distribución espacial de los barrios en la ciudad.

La ciudad de San Salvador de Jujuy combina tres tendencias de división social del espacio urbano. La primera es una segregación de tipo centro periferia, el nivel socio-económico de los habitantes desciende a medida que uno se aleja del centro. Este primer círculo está físicamente limitado por los dos grandes cursos de agua que atraviesan la ciudad (el río Grande y el río Xibi Xibi), formando una especie de isla. Estos cursos de agua son también importantes barreras sociales. Una segunda tendencia es una división social norte-sur. Al norte, al lado del río Grande, habita la población más acomodada, sea segregada con la construcción del primer barrio privado cerrado por muros, sea mezclada con poblaciones diversas. En oposición, al sur del río Xibi Xibi, el estándar social decrece. Se trata igualmente de una barrera étnica, la población de origen indígena (aunque tales orígenes sean muy lejanos) se encuentra sistemáticamente al sur de este curso de agua (Stumpo, 1992). La tercera tendencia es una división convexa y cóncava: las poblaciones socialmente desfavorecidas se instalan en viviendas precarias en los contornos de los lechos de los ríos, en los límites de las zonas inundables, a un nivel inferior del centro de la ciudad, mientras que las residencias de la burguesía ocupan las alturas al oeste y las laderas de las colinas al norte (García-Moritán, 1997). La combinación de estas tres tendencias define el orden socio-espacial de San Salvador de Jujuy. En este orden segregativo, cada uno tiene asignado su lugar.

Por lo tanto, al atender a las formas de estas estrategias, se puede decir que los ciudadanos jujeńos encontraron en los ríos que atraviesan su capital, en la distinción norte/sur y centro/periferia una clave para su estilo de imaginarla. Si consideramos entonces a los ríos Grande y Chico como líneas demarcatorias, podemos proponer en principio una zonificación de la ciudad en tres áreas: un área central, ubicada entre ambos ríos; un área que se extiende hacia el norte del río Grande; y una tercera que, a partir del río Chico, se extiende hacia el sudeste. Nombraremos a estas zonas central, norte y sur, respectivamente. Aunque con variaciones, estas tres

\footnotetext{
${ }^{21}$ La fase más reciente del desarrollo urbano en América Latina es denominada por Borsdorf (2003) como la ciudad fragmentada. En ella los contrastes no son a gran escala (ciudad rica/ciudad pobre) sino que elementos económicos y barrios habitacionales se dispersan y mezclan en espacios pequeńos. Diversos sectores se instalan en barrios cercados y amurallados para separarse y asegurarse. Por otro lado, se consolidan los barrios marginales antiguos que se transforman en casas de material, contando con infraestructura urbana, escuelas, mercados, tiendas, áreas verdes y plazas. Los barrios de grupos marginales emplazados en el centro están en proceso de disminución, en virtud de programas de renovación urbana o debido a presiones del mercado de suelos (Borsdorf, 2003).
} 
zonas son representadas/interpretadas por los habitantes de San Salvador de manera diferencial, en los términos que se indican a continuación. ${ }^{22}$

La zona central es vista como lugar de trámites y transacciones financieras, centro político, histórico y turístico; la zona norte se considera predominantemente residencial, con buenas vistas y alta calidad de vida; la zona sur es percibida como la más populosa y popular. Hay representaciones diferenciadas, altamente marginales, para los barrios y asentamientos que, si bien se ubican dentro de los ríos Grande y Chico, ocupan el lecho del río Grande. Más allá de estas consideraciones acerca del imaginario de San Salvador de Jujuy, y yendo a la descripción demográfica, la zona sur es la más densamente poblada, situación que se ha mantenido (y agudizado) en la década de 1990 (Bergesio y García, 2006).

Los datos poblacionales (del año 2001) permiten observar, así, el alto grado de desigualdad en la distribución de la población dentro de la ciudad. Mientras que en la zona central, que abarca 20\% del territorio de la ciudad, habita $12 \%$ de la población, en la zona norte, que ocupa $32 \%$ del territorio, habita $17 \%$ de la población; y en la zona sur, que representa $48 \%$ del territorio de la ciudad, vive $71 \%$ de la población de San Salvador de Jujuy. Esta última resulta así la zona más poblada, con 110.6 habitantes por hectárea, mientras ocupan la misma extensión 43.4 personas en la zona central y 39.6 en la zona norte ${ }^{23}$ (Bergesio y Golovanevsky, 2005). En esta zonificación se destaca un barrio de reciente formación, pero que ya concentra buena parte de la población de la ciudad, se denomina Alto Comedero. La concentración de población tiene un origen dual: migrantes provenientes del interior provincial, por un lado (subarrios de mineros, exempleados de Altos Hornos Zapla, extrabajadores cañeros) y pobladores de la capital provincial que no encuentran en zonas más céntricas la posibilidad de acceder a la vivienda, por el otro.

Alto Comedero se encuentra, podría decirse, al sur del sur, en un lugar geográfica y socialmente periférico. Es así una zona periférica de una provincia periférica de un país periférico: es un espacio separado de los grandes circuitos económicos de la mundialización (Fournier, 2002). De cierta manera, Alto Comedero ilustra la fragmentación de los territorios ligado a la acentuación de las desigualdades sociales en América Latina. (2003)

${ }^{22}$ Esta propuesta de semiotizar la ciudad y las representaciones es expuesta en García-Vargas

${ }^{23}$ Este proceso de concentración de la población en la zona sur es fortalecido desde la planificación por distintos ordenamientos, como el Plan Director Municipal (Ordenanza 628/86) y el Código de Planeamiento Urbano de la ciudad de San Salvador de Jujuy (Ordenanza 2363/96) que reglamentan el uso del suelo de las distintas zonas. 


\section{El barrio Alto Comedero: la nueva ciudad}

El barrio Alto Comedero está ubicado en el sur de San Salvador de Jujuy (mapa Iv). Este barrio se origina en un plan de viviendas en el año 1986 y en la actualidad cuenta con una población superior a los $60,000^{24}$ habitantes, lo que representa más de $20 \%$ de la población total de la ciudad (mapa I).

El barrio Alto Comedero tiene su origen en un plan de viviendas desarrollado a partir de 1986 con el propósito declarado de dar respuesta al déficit habitacional en la capital provincial. En ese año, el gobernador peronista de la provincia de Jujuy de aquel entonces, ingeniero Carlos Snopek con el objetivo explícito de poner fin a las denominadas invasiones ilegales de los terrenos privados en el entorno de la ciudad y suprimir las zonas de viviendas precarias (junto con el desorden social que esto representaba), decidió expropiar 600 hectáreas en el lugar denominado Alto Comedero, a cinco kilómetros de San Salvador de Jujuy, para destinarlas a la construcción de viviendas. El 17 de septiembre el gobernador firmó el decreto de expropiación, lo que constituyó un acto contrario al orden jurídico, ya que las expropiaciones, sobre todo de esta magnitud, deben normalmente ser hechas por ley votada por la Asamblea Legislativa de la provincia. Pero el gobernador buscaba ganar tiempo porque su mandato finalizaba en 1987 y perseguía su permanencia en el cargo. En esta ambición, la adjudicación de terrenos y viviendas era clave en términos electorales, sin duda, el objetivo no declarado que está en el origen del barrio Alto Comedero.

La asignación de los terrenos tuvo lugar cuando la campaña electoral para la gobernación ya había comenzado, por lo que el proceso de urbanización y el acceso a los terrenos urbanos fue directamente asociado,

\footnotetext{
${ }^{24}$ Esta cifra es desconocida en la actualidad y dependiendo de la fuente es 60,000 (Municipalidad de San Salvador de Jujuy a fines del año 2004), 70,000 (Instituto de Vivienda y Urbanismo de Jujuy en el año 2005), 80,000 (Centros vecinales de Alto Comedero en el año 2005). En declaraciones en un programa de radio de Jujuy, en febrero del 2007, el Secretario de Planificación del municipio capitalino se refiere a Alto Comedero como "... una ciudad con cerca de 100,000 habitantes". Y en octubre de ese mismo ańo un candidato a Intendente hablaba de 120,000 habitantes para Alto Comedero. Finalmente, una proyección de los datos censales para fines del año 2009 rondaría los 185,000 habitantes (cálculo propio), aunque tal estimación debe tomarse con cautela ya que el crecimiento intercensal se encuentra sobreestimado. Porque las proyecciones estadísticas de población se basan en la comparación entre los dos últimos datos conocidos, en este caso serían los de los censos de población de 1991 y 2001, respectivamente. Ahora bien, la captación de la información en Alto Comedero resultó deficiente en 1991, dado que en ese momento el barrio se estaba poblando a gran velocidad, cambiando su configuración día a día y complicando de esta manera la posibilidad de generar la cartografía adecuada y tenerla disponible en tiempo y forma para la correcta cobertura durante el operativo censal. Al resultar subestimada la población para 1991, el crecimiento intercensal 1991-2001 resulta inevitablemente sobreestimado, por lo que la cifra de 185,000 habitantes así calculada debe ser considerada sólo con fines ilustrativos.
} 


\section{Mapa IV}

Mapa Barrial de San Salvador de Jujuy

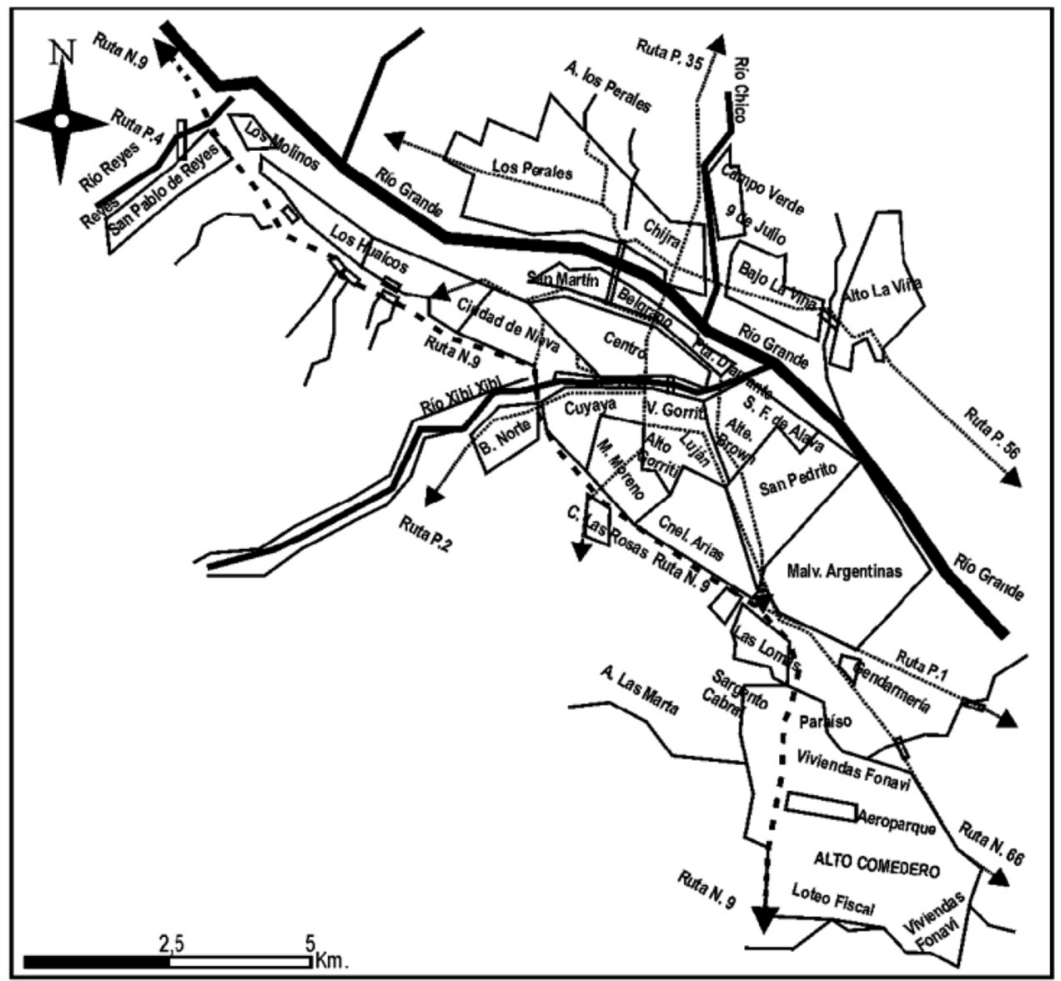

Fuente: Municipalidad de San Salvador de Jujuy.

por diversos actores sociales, al clientelismo político. ${ }^{25}$ Se produce así una distribución masiva de terrenos que no respeta los criterios previamente desarrollados en lo que se había dado en llamar una "operación integral de urbanización” (Gobierno de la Provincia de Jujuy, 1987). Los terrenos fueron distribuidos con criterios múltiples, pero es necesario destacar que hubo una notable mayoría de asignaciones a grupos familiares de bajos recursos económicos que no tenían vivienda propia.

La distribución de terrenos fue masiva, pero el gobernador no resultó reelegido. Cuando asumió el nuevo gobernador, el doctor Ricardo de Aparici, pocos meses después, el barrio volvió a estar presente en la agenda gubernamental y se buscó reorganizar la asignación de terrenos. Igualmente, las diversas instancias de esta nueva iniciativa también estuvieron

${ }^{25}$ El clientelismo político es entendido aquí como el intercambio personalizado de favores, bienes y servicios por apoyo político y votos entre masa y elites. Auyero (2000) plantea que, en los barrios pobres, asentamientos y villas, una de las maneras de satisfacer las necesidades básicas de alimentación y salud de los pobres es a través del partido político con acceso directo a los recursos estatales. 
permeadas por relaciones de tipo clientelar y, además, pronto se vieron en medio de un tormentoso tiempo político. Porque a partir de entonces, entre 1987 y 2001, nueve gobernadores han estado en el poder en la provincia de Jujuy, aunque un mandato dura normalmente cuatro ańos. Así, en la década de 1990, la historia jujeña se caracterizó por la crisis económica acompañada de inestabilidad institucional y social, a lo que se sumó el impacto de las políticas de ajuste de corte neoliberal. La nación exigía a los gobiernos provinciales reformas que los ahogaban financieramente, por lo que éstos apelaban a la reducción de salarios, atraso de pagos y despidos, generando las consecuentes protestas gremiales y sociales, que terminaban debilitando a los gobiernos y dando lugar a sus sucesivas caídas (Lagos y Gutiérrez, 2006).

Cada uno de los gobernadores actuó de alguna forma en Alto Comedero, plasmando concepciones personales, dictando medidas puntuales, la mayoría de las veces vinculadas con la proximidad de una elección política; es decir, se trataba de actos oportunistas, signados por el día a día, el grado de financiamiento disponible y el calendario electoral. Todo esto quedó reflejado en el proceso de constitución y posterior desarrollo del barrio.

Si acordamos que el ordenamiento del espacio geográfico es un medio de intervención social con el cual se pretende construir un nuevo orden urbano que suele perseguir distintos fines, en este caso el momento elegido para hacerlo no es un detalle menor. Porque se lleva a cabo en un tiempo político importante donde la construcción del barrio se vincula con aspiraciones políticas reeleccionistas concretas. Las elecciones y esas aspiraciones politicas que despiertan son inseparables con el crecimiento del barrio a lo largo de toda su breve historia, aunque sus protagonistas cambien, por ejemplo, en situación de entrevista un expresidente de un centro vecinal de Alto Comedero decía: "No hay ningún proyecto de Alto Comedero, no hay nada... Va creciendo, cada cuatro años, cada vez que hay elecciones, se puede hacer alguito. Pero no porque alguien estudió, sino porque a alguien le parecía bien en ese momento hacer eso y lo hacen”.

A diferencia de lo ocurrido en el gobierno provincial, durante prácticamente toda la década de 1990 San Salvador de Jujuy tuvo un único intendente, Hugo Cid Conde, quien fuera elegido en ese cargo en octubre de 1991 y permaneciera en el mismo hasta el 2003. En 1996, durante su gestión, el Concejo Deliberante capitalino sancionó el denominado "Código de Planeamiento Urbano de San Salvador de Jujuy". Si bien existieron tres planes anteriores de ordenamiento urbano (de los años 1958, 1970 y 1981), la ciudad siguió igualmente un desarrollo no planificado (García-Moritán, 1997) dado que lo proyectado nunca se plasmó en acciones concretas. Esta directriz se modifica con el Código aproba- 
do en 1996, donde el Estado organiza la radicación de planes de viviendas fortaleciendo la tendencia hacia una ciudad dual. Para el sector norte se impide la alta concentración, obligando a la parcelación en lotes más extensos, mientras que en las zonas centro y sur se permite una menor superficie en los lotes y se otorgan normas más flexibles para la construcción. En suma, esta nueva normativa refuerza la desigualdad espacial ya imperante (García-Vargas, 2009).

Alto Comedero es un barrio que por su conformación social se diferencia del resto de la ciudad, pero tampoco puede decirse que sea homogéneo en toda su extensión. Presenta zonas bien diferenciadas, las cuales también están plagadas de heterogeneidades internas, es decir, Alto Comedero no es un barrio socialmente uniforme, sino que tiene zonas diferenciadas con multiplicidad de situaciones y características al interior de cada una de ellas.

Esta diversidad se vincula, al menos en parte, con el propio origen y posterior desarrollo del barrio, que reconoce múltiples formas. Así, en la actualidad, en Alto Comedero se pueden identificar seis grandes mecanismos de crecimiento urbano:

1. Viviendas del sector público construidas por el Instituto de Vivienda y Urbanismo de Jujuy (IVUJ).

2. Áreas construidas con base en el financiamiento del Banco Hipotecario Nacional.

3. Lotes o terrenos llamados fiscales, que son terrenos viabilizados y para los cuales la construcción de viviendas está a cargo de los propios habitantes (autoconstrucción legal).

4. Ocupaciones de terrenos (llamados ilegales) a lo largo del curso del Arroyo Las Martas con autoconstrucción de viviendas precarias.

5. Loteos privados construidos sobre el contorno de la zona expropiada por el sector público.

6. Autoconstrucción por medio de cooperativas de trabajo con el apoyo del IVUj y con financiamiento a través del Plan Trabajar y Manos a la Obra (u otro plan social nacional) administrado por organizaciones sociales locales.

Los cinco primeros mecanismos se desarrollaron en la década de 1990 y, con la sola excepción de las viviendas financiadas por el Banco Hipotecario, continúan en el presente. En cambio el sexto mecanismo se inicia en los primeros años del presente siglo y también sigue vigente en la actualidad. Aproximadamente dos terceras partes de las viviendas de Alto 
Comedero corresponden a planes de viviendas del IVUJ, y el resto se distribuye en loteos y asentamientos. ${ }^{26}$

Con base en una encuesta realizada en el barrio Alto Comedero hacia fines del 2004, ${ }^{27}$ con un muestreo probabilístico en dos etapas, a la cual respondieron 250 hogares (un total de 1,225 individuos, de los cuales 908 tenían diez años y más), podemos afirmar que no existe un Alto Comedero, sino varios, por lo menos dos, bien diferenciados. Por un lado, están quienes accedieron a un plan de viviendas estatal (por lo general del IVUJ), y que por eso mismo, comunmente, tienen empleos públicos de ingresos medios. Por otro lado, están quienes se han instalado por su cuenta, en casi todos los casos, vía asentamientos, y se han autoconstruido viviendas en la mayoría de los casos inseguras, con escasos servicios y comodidades, según sus posibilidades. En este caso, se observan inserciones laborales precarias y alta presencia de planes sociales (generalmente, Plan Familias y Plan Jefes y Jefas de Hogar Desocupados). Según los datos obtenidos en la encuesta, la segunda fuente de recursos para los últimos tres meses de $84 \%$ de los hogares fue, según ellos mismos citan, la ayuda social.

Quienes pudieron obtener una vivienda del IVUJ suelen provenir de familias de recursos medios, con inserciones laborales no precarias y en sectores económicos de fuerte impacto en la economía provincial. Quienes ocupan los barrios de autoconstrucción, en muchos casos asentamientos de hecho, con tenencia aún precaria, muestran orígenes por lo general humildes, con presencia mayoritaria de progenitores originarios de zonas agrícolas-ganaderas del interior de la provincia, en algunos casos inmigrantes bolivianos, siendo las ocupaciones más comunes de los padres (durante la infancia de los encuestados) como obreros en algunas de las minas existentes en ese entonces, como empleados estacionales de los ingenios azucareros, y como peones rurales. Inclusive se detectan casos de cría de ganado para autoconsumo; es decir, la precariedad laboral parece transmitirse de generación en generación, y de padres que fueron obreros mineros, peones rurales o zafreros; tenemos, generalmente, hijos e hijas albañiles, cuentapropistas o desocupados.

Esta aproximación al barrio Alto Comedero permite entonces verlo como el lugar nutrido por dos tipos de población:

- Los migrantes del norte (de la provincia o de Bolivia) de bajos recursos e historias de pobreza, que ven al barrio como leve progreso en sus historias personales pero que sienten que todavía

\footnotetext{
${ }^{26}$ Diario Pregón, 11 de marzo de 2004.

${ }^{27}$ Los resultados completos se encuentran en Bergesio et al. (2009b).
} 
tienen muchas necesidades no cubiertas (sobre todo educación, seguridad y salud).

- Las jóvenes generaciones de la capital que han desbordado las viviendas existentes $y$, con empleos públicos o empleos formales en el sector privado, lograron el acceso a una vivienda ivUj o de algún plan sindical, que ven en Alto Comedero su única posibilidad en la actualidad pero que desearían vivir en otro barrio de la ciudad (más valorado socialmente).

En definitiva, Alto Comedero es una muestra más de la homogénea diversidad de destinos y trayectorias que sufrimos los habitantes de Argentina, en general, y los de Jujuy, en particular, en la etapa del modelo neoliberal encarnado en la convertibilidad. Homogénea, porque puede decirse que todos quienes viven en Alto Comedero fueron afectados de manera más o menos directa por el desempleo y la precarización del empleo, esto es, en definitiva, la reducción de los ingresos. Diversidad, porque no podemos considerar de la misma manera a quienes sufrieron estas consecuencias desde una vivienda precaria, autoconstruida en las márgenes de un cauce fluvial, con el dinero justo para el alimento diario, que a quienes pudieron enfrentar la pérdida de ingresos desde una vivienda digna, con alguna cobertura social y con vínculos sociales y familiares que acercaran un auxilio en el medio de la debacle.

\subsection{Alto Comedero: ¿Subproducto de las politicas neoliberales?}

Alto Comedero se ha desarrollado y crecido en la década de 1990, es decir, en la etapa de desarrollo del modelo neoliberal en Argentina. Alto Comedero refleja, de manera paradigmática, la crisis de ese periodo porque se fue habitando con base en, fundamentalmente, migrantes internos desocupados y familias con trabajadores precarizados. Aunque se han dado fenómenos similares en distintas ciudades del norte argentino (Bolsi, 2000) el crecimiento de Alto Comedero es particularmente interesante por su magnitud, sin precedentes, en la provincia de Jujuy.

Su crecimiento es tan notable que se lo denomina comúnmente nueva ciudad, puesto que su tamaño es equiparable al de la ciudad toda, al menos en la percepción de los habitantes de San Salvador de Jujuy y en su representación en los croquis de la ciudad. Aunque, es necesario decirlo, esta no es una fuente que logre reflejar en su totalidad las zonas habitadas/edificadas del barrio porque se van conformando loteos (viviendas autoconstruidas de tipo precario) que son incorporados en los planos de la ciudad, por lo general, mucho tiempo después de su conformación. Además, en los últimos años, se suelen organizar entre dos y cuatro sec- 
tores nuevos de viviendas construidas por el IVUJ por año (de entre doscientas a trescientas viviendas con un promedio de cinco a seis personas por vivienda $)^{28}$ que tampoco son incorporadas rápidamente al croquis de la ciudad. ${ }^{29}$

A pesar de este notable crecimiento, no se puede hablar de la creación de una ciudad en el sentido tradicional del término debido a la carencia de numerosas funciones urbanas, la insuficiencia de los servicios públicos y, sobre todo, a su dependencia administrativa, legislativa y financiera de la ciudad de San Salvador de Jujuy. Es posible entonces que se trate de un nuevo tipo de organización urbana periférica (geográfica y socioeconómica) producto no planificado de las políticas neoliberales implementadas durante las últimas décadas en Argentina y cuyas consecuencias no dejan de influir (y afectar) en la vida de todos los días (y el futuro) de sus habitantes.

La década de 1990 en Argentina estuvo caracterizada por un contexto económico con desempleo creciente, precarización laboral y empobrecimiento también en aumento. La participación en el ingreso del decil superior aumentó en casi 10\% entre 1980 y 2000. Tan sólo los ingresos de los patrones pasaron de ser 19 veces la línea nacional de la pobreza en 1980 a 24 veces en 1997. Los ingresos de los trabajadores informales descendieron sustancialmente en el mismo periodo. Durante la década de 1990, la razón ingreso/empleo de las clases dominantes se incrementó de 2.3 a 2.7 mientras que la del proletariado informal, permaneció estancada. El porcentaje de habitantes viviendo en situación de pobreza, que en 1980 correspondía a 5\%, aumentó hasta $38 \%$ para 2002, en la población del área metropolitana. Como resultado: "el país pasó de ser uno de los más igualitarios en la región, a evocar la tradicional desigualdad económica de sus vecinos" (Portes y Roberts 2005: 47). El porcentaje de hogares bajo la línea de la pobreza (LP) creció con fuerza en los noventa, y particularmente en la crisis 2001-2002. Según Gasparini (2006) entre 1992 y 2005 cayeron bajo la LP 8 millones de personas: 3.5 millones mientras la economía crecía en los noventa, 3.5 millones en la primera fase de la recesión (1998-2001), 7.5 millones en la crisis 2001-2002, mientras que 6.5 millones salieron de la pobreza con la recuperación posterior.

\footnotetext{
${ }^{28}$ Comunicación personal Dirección de Planificación Urbana de la Provincia de Jujuy.

${ }^{29}$ Otra fuente que puede acercarnos a una idea del crecimiento que tiene en un ańo Alto Comedero es la información publicada en un folleto oficial del Gobierno de la Provincia de Jujuy, donde se resume la gestión del gobernador en el 2004. Allí se afirma que en ese año se construyeron en Alto Comedero dos complejos habitacionales financiados por el ivuj con 302 viviendas para trabajadores mercantiles (Gobierno de la Provincia de Jujuy, 2005:24), y uno de 216 viviendas correspondiente al Plan de Emergencia Habitacional-Primera Etapa, financiado por el gobierno nacional y coordinado por la Central de Trabajadores Argentinos (cta), los Consejos Consultivos y los municipios (Gobierno de la Provincia de Jujuy, 2005: 17).
} 
Para el caso particular de Jujuy el empleo precario (sin protección social) entre los asalariados creció de $21.7 \%$ a $41.4 \%$ de este colectivo entre mayo de 1991 y mayo de 1999 , mientras que los datos sobre pobreza muestran que el porcentaje de hogares bajo la LP creció de $27.7 \%$ en mayo de 1985 a $46.7 \%$ en mayo de 1991 y $47.8 \%$ en mayo de $1999 .{ }^{30}$ La situación continuó siendo crítica en los primeros años del siglo XXI, alcanzando $57.3 \%$ de hogares bajo la LP para mayo de 2002. El ingreso medio mensual per cápita familiar en el Aglomerado San Salvador de Jujuy-Palpalá, que era 13 veces mayor en el decil 10 que en el decil dos para octubre de 1996, pasó a ser 16 veces mayor entre esos mismos deciles para octubre de 2002. El ingreso medio mensual de la ocupación principal se redujo en el Aglomerado San Salvador de Jujuy-Palpalá de 413 pesos en octubre de 1996 a 362 pesos en octubre de 2002, en ambos casos medidos a valores corrientes. ${ }^{31}$

Las políticas neoliberales aplicadas en la década de 1990 en América Latina enfatizaban la privatización de activos públicos, la liberalización de la economía y la macroestabilización como objetivos de la reforma. El Banco Mundial llevaba las puntuaciones de la rapidez con que países como Argentina privatizaban empresas del Estado. "Pero demasiado a menudo se olvida llevar la puntuación de la cantidad de individuos a quienes se les empuja a la pobreza, o de los empleos perdidos respecto de los que se crean, o del incremento de la violencia” (Stiglitz, 2001: 18).

\subsection{La hipótesis de implosión de población $n^{32}$}

Con base en el material recuperado hasta el momento surge la hipótesis de implosión ${ }^{33}$ de población, esto es, que el barrio va quedando sumido bajo una marea de inmigración proveniente de los barrios y localidades que la circundan como producto de la crisis socioeconómica que afectó a Argentina durante la década de 1990.

Elegimos hablar de implosión ${ }^{34}$ porque podemos encontrar similitudes con el uso que hizo de esta expresión Kumar Bose para el caso de Calcu-

\footnotetext{
${ }^{30}$ Estos datos son tomados de Golovanevsky (2002), y corresponden a estimaciones propias con base en microdatos de la Encuesta Permanente de Hogares (EPH) para el Aglomerado San Salvador de Jujuy-Palpalá.

${ }^{31}$ Estos últimos datos se obtuvieron del indec y pueden encontrarse en: Golovanevsky (2008).

${ }^{32}$ Esta hipótesis fue formulada y desarrollada por primera vez para el caso de Alto Comedero en: Bergesio y Golovanevsky (2004).

${ }^{33}$ Implosión: explosión desde afuera hacia adentro.

${ }^{34}$ Janoschka (2005: 152) emplea también el término implosión, pero en sentido inverso. Según él, la lógica de que las ciudades están siempre en constante expansión está siendo cambiada, y a principios del siglo xxi "se pueden observar cada vez más ciudades - no sólo europeas- donde se ha producido la inversión de la tradicional dicotomía entre la reducida oferta de viviendas en el mercado y la creciente demanda por parte de los hogares". Cada vez hay más viviendas desocupadas y
} 
ta. Esto es: "Un tipo de urbanismo tan imperfecto como el que acabamos de estudiar, dentro del marco de una economía de escasez - por no decir de hambre-, no tiene por menos que contribuir a aumentar las tensiones entre los grupos étnicos; tensiones que en efecto afloran, de tanto en cuanto, a la superficie con resultados desastrosamente divisorios" (Kumar, 1982: 96).

En nuestro caso, no se trataría de tensiones entre grupos étnicos (aunque el desprecio hacia lo boliviano está muy presente en muchos sectores), sino de la presión que significa el afrontar la supervivencia cotidiana en medio de la falta de oportunidades, el olvido del Estado y la amenaza siempre latente de la llegada de nuevos grupos, igualmente pobres y vulnerables, en busca de un lugar donde vivir.

Alto Comedero sigue siendo, entonces, un lugar de radicación para numerosas familias que no logran resolver de otra manera su requerimiento de una vivienda. En algunos casos, se trata de población que no tiene los medios para establecerse en zonas más cercanas al centro de la ciudad (empleados públicos, asalariados registrados del sector privado con ingresos medios, que logran adjudicación de viviendas del IVUJ o que están en condiciones de llevar a cabo autoconstrucción legal). En otros casos, son migrantes de otras partes de la provincia que llegan a la capital en busca de los ingresos que no consiguen en su lugar de origen, y que deben procurarse, como sea, un lugar para vivir (asentamientos, autoconstrucción ilegal). Como una muestra de las épocas que corren, y dando testimonio de la importancia de la autoorganización comunitaria y de los nuevos movimientos sociales, se inserta también en Alto Comedero la construcción vinculada a organizaciones sindicales, como la CTA. Dicho en otras palabras, homogeneidad y diversidad, en un destino común de vulnerabilidad e incertidumbre ante el futuro. La incertidumbre ha sido una característica histórica en la vida del hombre a "lo largo de la mayor parte de la historia humana, la gente ha aceptado que la vida cambia de repente por culpa de las guerras, las hambrunas y otras catástrofes, y también que, para sobrevivir, hay que improvisar" (Sennet, 2000: 30).

Pero lo que tiene de diferente y particular el escenario actual es que la incertidumbre "existe sin la amenaza de un desastre histórico y, en cambio, está integrada en las prácticas cotidianas de un capitalismo vigoroso" (Sennet, 2000: 30). Es decir, este contexto de incertidumbre y vulnerabilidad no es patrimonio exclusivo de los sectores más pobres o de los países menos desarrollados, sino que es común a todos los hombres y a todos los países. Sin embargo, aceptando que se trata de un mal ge-

destruidas, dando lugar a la transformación de la ciudad dispersa en ciudad perforada, debido a la eliminación de edificios y barrios enteros del medio urbano. Este uso del término implosión es, entonces, diametralmente opuesto al que le damos para el caso de Alto Comedero. 
neral característico del tiempo que nos toca vivir, es innegable que estar inserto, como ya se dijo, en un barrio periférico de una provincia periférica de un país periférico no puede sino agravar este mal común y hacer más graves sus consecuencias.

\section{San Salvador de Jujuy y sus muros de cristal}

La ciudad de San Salvador de Jujuy evidencia marcados contrastes que son las consecuencias territoriales de la implementación del reciente modelo de acumulación. Este afecta a las regiones del interior del país y se suma a desigualdades de larga data, en una configuración particular.

En ella, en cerca de veinte años, ha surgido una verdadera concentración urbana paralela, con una población estimada al 2009 de 185,000 habitantes ${ }^{35}$ denominada Alto Comedero, llamada localmente la nueva ciudad. La cual puede verse como el resultado de una implosión de población, producto de las migraciones internas en el marco de las consecuencias del neoliberalismo en la provincia. ${ }^{36}$ En este sentido, puede señalarse que "como en otras ciudades, en San Salvador de Jujuy la discusión por el espacio físico se vincula con la construcción del espacio social, y ambas se configuran sobre la base de una operación doble de historización y especialización de la desigualdad y las diferencias" (García-Vargas, 2009: 391-392). Lo que nos interesa en este caso es cómo estos procesos se dan de manera especial y única en esta ciudad.

Como ya se dijo en la Introducción de este artículo, consideramos que al espacio como una vía para tratar de comprender la dinámica más amplia de los hechos sociales. En particular, en el caso de Alto Comedero, y dentro de su diversidad, esta perspectiva espacial parece apropiada para estudiar los procesos de destitución, es decir, miramos la concentración geográfica de la pobreza o, lo que es lo mismo, "la acumulación de distintos tipos de privación en territorios de relegación" (Auyero, 2001: 22).

Queda claro que el neoliberalismo no sostuvo (al menos en este caso) un Estado ausente. Si bien favorece un Estado que se repliega de sus funciones sociales y reguladoras, por otra parte incrementa el pago de intereses de la deuda pública, desfinancia el sistema de seguridad social y aumenta la carga tributaria sobre los sectores de menores recursos. Todo ello se produjo mientras se facilitaba "la apropiación de renta por los capitales más concentrados e incluso el incremento sustancial de la remisión de utilidades al exterior" (Bergesio y Fandos, 2009c: 49). Es decir, el retiro del Estado podría calificarse de aparente, porque en realidad,

\footnotetext{
${ }^{35}$ Véase: Nota al pie número 24 de esta investigación.

${ }^{36}$ Este fenómeno también se ha dado en la periferia de otras grandes ciudades de la provincia, aunque con posterioridad a lo ocurrido en Alto Comedero.
} 
lejos de disminuir su importancia, ha desempeñado un rol fundamental en la defensa de los intereses de los grupos dominantes, garantizando la lógica regresiva de "un modelo impuesto por una elite dominante, que encuentra en el desempleo, en la fragmentación social y en los crecientes grados de polarización a su arma más efectiva para alcanzar sus objetivos de acumulación de la riqueza nacional" (Gambina, 2001: 224).

Ahora bien, ¿por qué consideramos que la situación social del barrio Alto Comedero puede ser relevante para comprender fenómenos más globales de las urbes latinoamericanas? Porque entendemos que este barrio, con una cantidad tan significativa de población, refleja de manera paradigmática la crisis socioeconómica de la década de 1990 en Jujuy, en particular, y en Argentina, en general, visibilizando la reconfiguración de la estructura urbana que construyó.

La crisis socioeconómica tuvo consecuencias directas en la vida de quienes la sobrellevamos. Tales como: el empobrecimiento de los sectores medios y la creciente vulnerabilidad social de los sectores empobrecidos y pobres. ¿Qué hizo el Estado en este caso en San Salvador de Jujuy? Ofreció un lugar de la ciudad, separado y separable, para que estos crecientes grupos accedieran a una vivienda mediante créditos a largo plazo (fundamentalmente del IVUJ) o mediante autoconstrucción. Pero su presencia es insuficiente en salud, educación, seguridad, calidad de la vivienda, de la infraestructura y del entorno urbano. Sin embargo, el Estado tampoco se ha desvinculado del todo de esta población, la ayuda social (en forma de subsidios mensuales que no llegan a cubrir $20 \%$ del costo de la canasta familiar básica) constituye un porcentaje muy importante de los ingresos de estas personas, si es que no son, directamente, obreros o empleados del sector público (Bergesio et al., 2009b).

Recuperando esta idea, de nueva ciudad, pero con otro significado, tal vez pueda pensarse al barrio Alto Comedero como una expresión de un nuevo modelo de ciudad que concentra en sus márgenes menos visibles a la población pobre o empobrecida. Es que tanto desde las vías de mayor circulación - por ejemplo la ruta nacional 9 de acceso a la ciudad- ${ }^{37}$, como desde el centro de San Salvador de Jujuy o desde los barrios más valorizados, Alto Comedero aparece como separable o invisible, según el caso. ${ }^{38}$

\footnotetext{
${ }^{37}$ Si bien Alto Comedero está a un costado de la ruta de entrada desde el sur a San Salvador de Jujuy, el barrio queda a cierta distancia de la ciudad en sí, por lo que la percepción es claramente de barrio separado. A diferencia, por ejemplo de la Villa 21 en Buenos Aires que quedó en el corazón de la ciudad, como muchos otros barrios populares formados en las décadas de 1960 y 1970 en Argentina.

${ }^{38}$ Un ejemplo de esta invisibilidad es el cartel que da la Bienvenida a quienes ingresan a San Salvador de Jujuy desde el sur. Este cartel se ubica a una altura tal (donde termina Alto Comedero y se une al entramado urbano) que quien ingresa ya pasó por Alto Comedero cuando se le recibe en la ciudad.
} 
Parecería así que se está planteando un diseño de ciudad, ejecutado desde el propio Estado, que promueve la tajante separación espacial de sectores sociales dentro de ella, con acceso también diferencial a los servicios. En este esquema, Alto Comedero podría ser definido como un barrio para pobres y empobrecidos con escasa infraestructura de servicios y muy alto índice de población.

En la construcción de este gran conglomerado urbano, decíamos, el Estado no estuvo ausente, sino que fue un agente activo y definitorio ya que colaboró en el rediseño de una ciudad claramente diferenciada en zonas. Por un lado, barrios cerrados, de propiedad privada pero con infraestructura estatal de agua, luz, gas, vías de acceso, etc. Por otro lado, barrios abiertos pero en terrenos para alto y medio poder adquisitivo, con edificaciones con todos los servicios y de medio o alto costo (algunas de ellas construidas incluso con financiamiento estatal a través del IVUJ, como los planes de viviendas para el Colegio de Arquitectos, Contadores, Médicos y otros). En cualquiera de estos dos casos se trata de viviendas ubicadas en zonas de media o alta valoración social (zona centro y norte de la ciudad). Finalmente, en el otro extremo de la división social y hacia el sur de la ciudad, se construyeron barrios con escasos servicios y casas de bajo costo, hechas con materiales de segunda calidad y, por ello, con serios problemas estructurales, en zonas con baja valoración social y con cierta lejanía del resto de la ciudad.

Ahora bien, esta separación de barrios en la ciudad que corresponde con una división social no es ni novedosa ni privativa de las últimas décadas; lo particular y novedoso en este caso (Alto Comedero) es el ritmo (en poco menos de 20 ańos), la magnitud (más de 100,000 personas) y la lejanía (el sur del sur) de esta concentración popular que modifica radicalmente la geografía urbana. Porque el proceso de construcción de la nueva ciudad en los albores del siglo xxi "tiene un fuerte componente de destrucción ciudadana, esto es, la destrucción real de la ciudad material, de sus mecanismos de integración tradicionales y de sus mínimos denominadores culturales comunes" (Katzman et al., 2005: 443).

Entonces, en algo más de veinte años ha surgido en Alto Comedero, una verdadera concentración urbana paralela, caracterizada por una masiva concentración de población pobre y empobrecida. Así, hombres y mujeres (en su mayoría con bajo o medio nivel de instrucción formal) conviven en la periferia de la ciudad, en un barrio heterogéneo que contiene sectores o zonas bien diferenciadas con desigual acceso a los servicios sociales, aunque en todos los casos sean deficitarios. Y aunque no es en sí una ciudad, es posible que se trate de un nuevo tipo de organización urbana periférica resultante de las políticas neoliberales implementadas 
durante las últimas décadas en Argentina. Esto es, un espacio donde se concentran distintos tipos de privaciones.

Alto Comedero se ha convertido en los últimos veinte años de modernidad excluyente (Barbeito y Lo Vuolo, 1992) en un enclave de nuevos pobres (o sectores medios empobrecidos) con manchones de pobres estructurales. Este enclave de pobreza en la ciudad es organizado por el propio Estado (a través del IVUj y otros planes sociales destinados a la construcción de viviendas para los más pobres), con el orden político interviniendo de manera permanente desde el propio origen del barrio. Por eso Alto Comedero sólo se entiende si se lo mira en relación con el resto de la ciudad y se considera, a su vez, el contexto amplio (económico, político, social) en el cual nace y se desarrolla. Porque la historia de esta configuración socioespacial es producto de una particular interacción entre fuerzas macroestructurales, políticas estatales, y el compromiso activo de los habitantes del barrio (tanto en cuanto individuos como a través de sus organizaciones colectivas) con esas presiones externas.

En la primera década del siglo xxi el modelo económico parece haber cambiado, la devaluación favoreció la recuperación del sector agroexportador y de la sustitución de importaciones. El neoliberalismo es denostado en los discursos oficiales. Si bien los salarios se han ido recuperando, los niveles de desigualdad se han profundizado. En el caso de Jujuy han emergido organizaciones sociales que, representando a los grupos desfavorecidos, han alcanzado una fuerza notoria, lo que les ha valido obtener posiciones cada vez más influyentes a nivel local. Pese a esto, la tendencia hacia la exclusión y estigmatización territorial no se ha interrumpido. Es hora de preguntarse entonces, si con la recuperación económica (por momentos promisoria, por momentos aparentemente inestable, en cualquier caso indiscutible a la fecha) no es suficiente, y el Estado no recupera su rol conductor ¡cuál será el futuro de estas ciudades fragmentadas, donde la separación tácita e invisible (como un muro de cristal) sigue dividiendo a la sociedad jujeña? 


\section{Conclusiones: la ciudad desgajada luego del diluvio neoliberal ${ }^{39}$}

En este artículo presentamos las consecuencias de las políticas neoliberales de la década de 1990 en Jujuy, a partir del estudio de los cambios en el entramado urbano de su ciudad capital. ${ }^{40}$ En particular, nos focalizamos en el surgimiento y desarrollo explosivo en ese periodo de un barrio al sur de dicha ciudad: Alto Comedero.

Tratando de responder a este objetivo, discutimos también cuáles fueron los cambios que en términos territoriales implicaron no sólo las políticas neoliberales sino también la reestructuración de la economía mundial. A nivel local Kanitscheider (2007) sostiene que las consecuencias de las políticas desarrolladas durante la década de 1990 en Argentina, toman en San Salvador de Jujuy rasgos muy diferentes a lo observado en las metrópolis como Buenos Aires. Esto podría deberse a que los procesos de transformación de los años noventa se encontraron en Jujuy con una ciudad capital que aún exhibía los típicos rasgos coloniales en el sentido del modelo de la ciudad latinoamericana. Así, el orden colonial del declive social del centro a la periferia se ha conservado casi sin alteraciones. Al respecto, García-Vargas (2009) plantea que, si bien las transformaciones territoriales vinculadas al neoliberalismo en San Salvador de Jujuy no condicen con aquellas que se destacan como típicas (como por ejemplo, la ausencia de barrios privados o shopping centers en la ciudad durante la década de 1990) y se adjudica ello al tamaño y la estrechez de recursos de esta ciudad, la ciudad capital de Jujuy no escaparía al modelo general, sólo que llegó al mismo con un cierto rezago. Así, García-Vargas (2009) describe cómo los proyectos para la construcción de barrios privados y del primer shopping center de la ciudad ${ }^{41}$ surgen a comienzos del siglo XXI, con idénticas formas de presentación y estrategias publicitarias que en otras ciudades. "Nos encontramos, entonces, con la emergencia de estos proyectos con cierto retraso respecto a otros puntos urbanos, pero similares objetivos de segregación y parecidas formas de interpretación del espacio urbano" (García-Vargas, 2009: 391). Es decir, en San Salvador de Jujuy las tendencias hacia la fragmentación, segregación y guetificación,

${ }^{39}$ La expresión diluvio neoliberal es recuperada del trabajo de Borón (2003).

${ }^{40}$ A diferencia de lo señalado en el epígrafe, la incidencia de las industrias y los barrios obreros han ido declinando y, en el caso particular de San Salvador de Jujuy, nunca llegó a ser un aspecto central.

${ }^{41}$ El primer shopping de Jujuy se ubica a media cuadra de la plaza central de San Salvador de Jujuy y su inauguración se concretó en el mes de octubre del año 2009. Cabe destacar, sin embargo, que a diferencia de otros casos, como el de la vecina ciudad de Salta, el shopping de Jujuy obedece a un emprendimiento de capitales locales (de la familia dueńa de uno de los dos diarios de mayor circulación en la provincia), no formando parte de ninguna cadena extra regional o internacional. 
consecuencia de las políticas neoliberales de la década de 1990, demoraron en llegar más que en otras ciudades, pero finalmente también lo hicieron.

Nos planteamos entonces la similitud o divergencia de los procesos de expansión urbana observados en la capital jujeña con aquellos acaecidos en el área metropolitana del Gran Buenos Aires. Al respecto, algunos rasgos aparecen compartidos, aunque en ocasiones no tengamos una explicación para este parecido. En particular, la zona norte en San Salvador de Jujuy, al igual que en Buenos Aires, se ha ido poblando con las clases medias, medias-altas y altas, quedando la zona sur para una parte de las clases medias pero, básicamente, para las clases medias-bajas y bajas. Esto configuraría un declive de norte a sur y no de centro a periferia, como lo plantea Kanitscheider (2007).

En cualquier caso, tanto en el norte como en el sur se están generando nuevos espacios en la ciudad, siempre respetando el orden recién señalado. El Estado no está ausente. Como ya se dijo, fue el principal impulsor del barrio Alto Comedero en el sur y también participa en la generación de infraestructura para la expansión de los barrios acomodados de la zona norte. De esta manera, el Estado es el principal artífice en la generación de un barrio separado y separable como Alto Comedero, profundizando así las tendencias de fragmentación, segregación y guetificación dentro de la ciudad.

En este sentido, Alto Comedero es singular, puesto que agrupa en un solo y enorme espacio un conjunto de población de bajos recursos (en la mayoría de los casos), lo que no se observa con la misma magnitud en Buenos Aires (donde se verían más vale manchas de pobreza de tamaño mucho más reducido), tal vez por la falta de disponibilidad de una extensión amplia de tierras, como sí es posible en San Salvador de Jujuy.

En dicha ciudad, entonces, el centro pierde fuerza como lugar residencial y la gana como zona comercial y financiera, mientras que el norte toma impulso como área residencial. En un proceso ya conocido, también hay población carenciada que se instala en zonas aledañas al centro, pero no recomendables para vivienda, en el margen de los ríos que atraviesan la ciudad.

Es decir, lo que se va profundizando es la separación de ricos y pobres. Los ricos no llegan a los barrios pobres y viceversa. No hay tránsito entre ambas zonas, excepto para ocasiones de delito. Pero esta falta de circulación no es porque haya un impedimento (no estamos hablando de barrios cerrados), hay unos muros de cristal que llevan a que cada grupo no invada el territorio del otro. Muchos niños que viven en Alto Comedero no conocen la Plaza Belgrano, en el centro de San Salvador de Jujuy, pese a su cercanía. 
Con la falta de movilidad social desaparece también el tránsito entre zonas ricas y pobres. Mientras los ricos se amurallan en barrios cerrados y countries buscando básicamente espacios protegidos de la amenaza de la delincuencia (Svampa, 2001 y 2004), el tejido social se resquebraja con nuevos y borrosos límites entre lo legal y lo ilegal. Estas conductas fronterizas se originan fundamentalmente en la inestabilidad laboral padecida por más de una generación de individuos, que por lo tanto desconoce inserciones laborales de calidad, carencia que se repite en padres e hijos. Para ellos, la relación con el trabajo se ha vuelto instrumental y, por lo tanto, intercambiable con otras formas de obtener recursos, como el delito (Kessler, 2008). Las políticas que dieron lugar a la desaparición del trabajo asalariado como forma privilegiada de inserción social, implementadas en Argentina durante la década de 1990, terminaron generando consecuencias que a su vez repercuten en el espacio urbano, y cuyos efectos no han dejado de afectar las vidas de las personas y la estructura social de la ciudad. Los barrios peligrosos, vistos como aguantaderos, se asocian en muchos casos mecánicamente a la pobreza, generando un estigma que refuerza los mecanismos de fragmentación y segregación, estableciendo nuevos guetos urbanos.

Consideramos que los tres términos -segregación, fragmentación y gueto- resultan pertinentes para el análisis. Un grupo de población se aglomera de manera involuntaria en un área determinada de la ciudad (segregación), la cual se encuentra separada socialmente del resto (fragmentación), y esta población así reunida resulta en la mayoría de los casos explotada desde el punto de vista de su participación en las actividades económicas (gueto). Si bien los tres conceptos pueden no darse plenamente, entendemos que en Alto Comedero reside una numerosa población allí atraída por la posibilidad de tener un lugar donde vivir (lo que no podía obtener en otras áreas de la ciudad), por lo que la coacción o involuntariedad vendría dada por su necesidad de albergue. Este barrio está de hecho separado del resto de la ciudad, no sólo por la distancia geográfica, sino también por la distancia social entre quienes, en razón de la época o de la disponibilidad económica, han logrado otras soluciones habitacionales en territorios mejor integrados. Finalmente, quienes viven en Alto Comedero comparten una condición proletaria, aunque pueden registrarse casos de pequeños empresarios o cuentapropistas, quienes por sus características se asemejan más a la clase obrera asalariada que a las clases medias o altas. Si bien la definición de gueto en el sentido estricto de Wacquant (con su contenido racial y de ostracismo social) podría no responder al caso de Alto Comedero, la imagen que el concepto de gueto evoca parece ajustarse, al menos en parte, a la situación del barrio; es 
decir, vivir en Alto Comedero se asocia con un cierto estigma, que no alcanza a otras barriadas igualmente populares de San Salvador de Jujuy.

A diferencia de épocas previas, la fragmentación presente en el espacio urbano parece cada vez más difícil de superar. La brecha entre ricos y pobres se hizo más amplia, y la movilidad social se redujo enormemente, por lo que, aunque puede ser posible convertirse en pobre sin haberlo sido antes, parece casi imposible pasar a ser rico desde una situación de pobreza. Y esto se refleja en el entramado de las ciudades con áreas donde radican los sectores sociales con mayores recursos económicos. Estas áreas tienen buenas vistas y vías de acceso convenientes; sistemas de recolección de residuos eficientes, seguridad privada, ambientes con escasa contaminación y amplios terrenos donde se levantan viviendas de alta calidad en su construcción e infraestructura urbana. Pero hay otras áreas de la ciudad con escasa o nula seguridad, donde el transporte público es irregular, abundan los basurales y las zonas inundables y en las casas construidas por el Estado habitan las familias de quienes trabajan como empleados públicos o en pequeñas empresas privadas, los maestros, los policías y los beneficiarios de planes sociales. Las áreas más ricas al norte, las más pobres al sur. Hay ahora una gran distancia (social y geográfica) que los separa y parece agudizarse rápidamente con el correr del tiempo, es decir, en un tiempo breve se han profundizado las separaciones socioespaciales en la ciudad.

Sin embargo, esta situación no es novedosa en sí misma. La segmentación es anterior al neoliberalismo, pero lo que sus consecuencias sociales generaron es la agudización de la fragmentación social con la consecuente guetización de la pobreza, donde el porcentaje de población que no encuentra otra alternativa habitacional a estos anclajes de pobres y empobrecidos, es superior al que sí lo consigue. Es decir, el caso que aquí analizamos deja al descubierto que el Estado (mediante planes de vivienda) es el que relega a un importante porcentaje de su población (la quinta parte de los habitantes de una ciudad intermedia latinoamericana) a espacios urbanos con escasos servicios e infraestructura (escuelas, policía y hospitales, por sólo nombrar los más notorios). El modelo vigente de exclusión social se expresa así en el espacio urbano a través de un nuevo patrón, que algunos autores denominan ciudad posfordista, ciudad global o ciudad cuarteada, "caracterizada -entre otras cosas- por la expresión de una nueva periferia, que presenta enormes contrastes respecto del modelo anterior, visibles en el aumento de la segregación interna y los procesos de dualización espacial" (Svampa, 2004: 16).

El neoliberalismo entonces parece haber generado una fragmentación de las ciudades, separando sectores sociales. Mientras que en el modelo IsI el espacio urbano funcionaba con un centro y una periferia no margi- 
nal, sino de barrios obreros, con aspiraciones de movilidad social ascendente, con autoconstrucción, en el modelo neoliberal el Estado hace las viviendas y acumula a los pobres en una zona en particular, alejándolos de los sectores de la ciudad donde vive la población con mayores recursos económicos.

Por el momento, parecería que este modelo sigue vigente, sin proyectos alternativos. En la medida en que estas políticas se repiten en las ciudades, las huellas se profundizan y se renuevan, volviéndose cada vez más difíciles de revertir. Estos procesos de relegación de grupos desfavorecidos a zonas alejadas e invisibles dejan marcas indelebles en el imaginario y en las subjetividades. Pero también en las condiciones materiales de vivienda, porque estos grupos desfavorecidos viven en lugares contaminados, donde el recolector de residuos pasa con menor frecuencia que en otros lugares, donde hay mayor inseguridad y menos escuelas y servicios de salud. Además, cuando un recurso escasea, como el agua potable por ejemplo, se elige asegurar el suministro a los barrios más favorecidos antes que a quienes viven en la periferia. $\mathrm{O}$ cuando se requiere reforzar la custodia de algún otro punto de la ciudad, se reduce al mínimo, hasta casi desaparecer, la presencia policial. Todos ejemplos del lugar, no sólo geográfico, que ocupan los habitantes de Alto Comedero en el entramado social de Jujuy.

En el espacio urbano se expresan los quiebres de la estructura social, profundizados por la aplicación de políticas de corte neoliberal. Barrios de relegación que se separan cual gajos amargos, por medio de muros de cristal (invisibles pero aparentemente irrompibles), donde varios temen caer, donde muchos han caído. En esta ciudad de modernidad excluyente, los mecanismos tradicionales de integración han desaparecido como reflejo, entre otras cosas, del papel que el Estado ha desempeñado. Como señalaba un dirigente barrial del barrio Alto Comedero:

Y ustedes que van a investigar se van a enfrentar a una sociedad así, dispuesta [...] a hacer lo que le digan, dispuesta a encubrir un montón de cosas, que ni saben qué hacen, ni les interesa qué hacemos en esta vida, para qué estamos. Parece que tenemos que tener hijos y que se críen como puedan, nada más. El futuro a nadie le interesa. A nadie nos importa el futuro, no nos importa nada, hay que tratar de vivir el momento. Ese es el gran problema que tenemos en esta sociedad. Y especialmente ahí, en Alto Comedero, a pocos le interesa que se pueda hacer algo. Una que no tienen esperanza y otra que ya el gobierno les ha quitado [...] nos bajó la autoestima, nos hizo creer que no podemos hacer nada por sí solos. Ya van a ver, gente tranquila, chicos medio agresivos, pero nadie tiene adonde ir, nadie tiene nada en Alto Comedero. 


\section{Bibliografía}

Auyero, Javier (2000), “Cultura política, destitución social y clientelismo político en Buenos Aires. Un estudio etnográfico”, en Maristella Svampa (ed.), Desde abajo. La transformación de las identidades sociales, Universidad Nacional de General Sarmiento-Editorial Biblos, Buenos Aires, pp. 181-208.

Auyero, Javier (2001), "Introducción. Claves para pensar la marginación”, en Loïc Wacquant, Parias urbanos. Marginalidad en la ciudad a comienzos del milenio, Manantial, Buenos Aires, pp. 9-31.

Barbeito, Alberto y Rubén Lo Vuolo (1992), La modernidad excluyente, unICEF-CIEPp-Losada, Buenos Aires.

Barsky, Andrés (2000), "Auge y ocaso de las 'Regiones geográficas argentinas de Federico Daus'”, Actas del Segundo Encuentro Internacional, Centro Humboldt, 23-27 de octubre, Mar del Plata.

Bauman, Zygmunt, "El estado benefactor volvió para los ricos", Revista N, 18 de julio 2009, Buenos Aires, p. 7.

Bellet-Sanfeliu, Carmen y Josep María Llop Torné (2004), “Ciudades intermedias: entre territorios concretos y espacios globales”, Ciudad y Territorio. Estudios Territoriales, XXXVI, Ministerio de Vivienda, Madrid, www.eukn.org/espana/themes/Urban_Policy/ Urban_environment/ciudades_intermedias_1268.html, 27 de octubre de 2009.

Bergesio, Liliana (2000), Ganarse la vida. Trabajadores cuentapropia del sector familiar en la estructura socioeconómica de San Salvador de Jujuy, Fundandes-FHycs-Unju, San Salvador de Jujuy.

Bergesio, Liliana y Laura Golovanevsky (2004), "Un fenómeno llamado Alto Comedero. Crisis económica y crecimiento demográfico en San Salvador de Jujuy. Revisión Bibliográfica y diagnóstico preliminar", www.naya.org.ar/congreso2004/ponencias.htm, 16 de octubre de 2009.

Bergesio, Liliana y Laura, Golovanevsky (2005), "Vulnerabilidad y pobreza en la Nueva Ciudad. El caso del barrio Alto Comedero en 
San Salvador de Jujuy", Actas del vir Congreso Nacional de Estudios del Trabajo (ASET), ASET, 10-12 de agosto, Buenos Aires.

Bergesio, Liliana y Alejandra García-Vargas (2006), “'Orden’ cartográfico y 'desorden' en las veredas. Trabajo en las calles y espacios públicos en San Salvador de Jujuy durante la década de 1990”, Actas del VIII Congreso Latinoamericano de Ciencias de la comunicación, Asociación Latinoamericana de Investigadores de la Comunicación (AlaIC) y Universidad do Vale do Rio dos SinosPrograma de Pós-Graduaçâo em Ciencias da ComunicaçâoUnisinos, 19 e 21 de julio, Sâo Leopoldo, Río Grande do Sul.

Bergesio, Liliana, Alejandra García-Vargas y Laura Golovanevsky (2008), "Continuidades, desplazamientos y rupturas en los procesos de estructuración/desestructuración espacial en San Salvador de Jujuy", Actas de las V Jornadas de Sociología de la UnLP y I Encuentro Latinoamericano de Metodología de las Ciencias Sociales, Departamento de Sociología-Facultad de Humanidades y Ciencias de la Educación-Red Latinoamericana de Metodología de las Ciencias Sociales-Cimecs-unlp, 10-12 de diciembre, La Plata.

Bergesio, Liliana, Laura Golovanevsky, María Elena Marcoleri (2009a), "Privatizaciones y mercado de trabajo: la venta de empresas públicas en Jujuy y sus consecuencias sobre el empleo", en Marcelo Lagos (comp.), Jujuy bajo el signo neoliberal. Politica, economia y cultura en la década de los noventa, EDIunju, San Salvador de Jujuy, pp. 185-249.

Bergesio, Liliana, Laura Golovanevsky y María Elena Marcoleri (2009b), Construcción social de la ciudad. San Salvador de Jujuy desde el barrio Alto Comedero, Ediunju, San Salvador de Jujuy.

Bergesio, Liliana y Cecilia Fandos (2009c), "Neoliberalismo: ideología y práctica. Su influencia en América Latina de los noventa", en Marcelo Lagos (comp.), Jujuy bajo el signo neoliberal. Politica, economía y cultura en la década de los noventa, Ediunju, San Salvador de Jujuy, pp. 13-63.

Bolsi, Alfredo (2000), "La población urbana-rural del noroeste argentino en el siglo xx”, en Marta Panaia, Susana Aparicio y Carlos Zurita (coords.), Trabajo y población en el noroeste argentino, La Colmena, Buenos Aires, pp. 41-58. 
Borón, Atilio (2003), "La sociedad civil después del diluvio neoliberal", en Emir Sader y Pablo Gentilli (comp.), La trama del neoliberalismo: mercado, crisis y exclusión social, Clacso/Eudeba, Buenos Aires, pp. 51-92.

Borsdorf, Axel (2003), "Cómo modelar el desarrollo y la dinámica de la ciudad latinoamericana”, Revista EURE, vol. XXIX (86), Pontificia Universidad Católica de Chile, Santiago de Chile, pp. 37-49.

Borsdorf, Axel, Rafael Sánchez y Carla Marchant (2008), “Aprendiendo de los errores. La necesidad de cambios a la política nacional de vivienda en ciudades intermedias chilenas", Actas del X Coloquio Internacional de Geocrítica, Universidad de Barcelona, 26-30 de mayo, Barcelona.

Carlos, Ana (1997), "La cuestión de los 'guetos urbanos", Actas del vi Encuentro de Geógrafos de América Latina, Instituto de Geografía, Facultad de Filosofía y Letras-UbA, 17-21 de marzo, Buenos Aires.

Cerrutti, Marcela y Alejandro Grimson (2005), "Buenos Aires, neoliberalismo y después”, en Alejandro Portes, Bryan Roberts y Alejandro Grimson (eds.), Ciudades latinoamericanas. Un análisis comparativo en el umbral del nuevo siglo, Prometeo Libros, Buenos Aires, pp. $75-147$.

Delgado, Fanny, Cecilia Fandos y Salomé Boto (2006), "Mundo urbano y agrario: los valles centrales", en Ana Teruel y Marcelo Lagos (dirs.), Jujuy en la historia. De la colonia al siglo XX, UNIHR-FHyCsEdiUnju, San Salvador de Jujuy, pp. 403-464.

Diario Pregón, "Alto comedero: la nueva ciudad", XLVIII, 17-178, 11 de marzo de 2004.

Fournier, Jean-Marc (2002), "Ordres et désordres dans les villes argentines, l'exemple de Alto Comedero, San Salvador de Jujuy", Annales de géographie, núm. 624, Armand Colin, Paris, pp. 179-197.

Gambina, Julio (2001), "Estabilización y reforma estructural en la Argentina (1989-1999)", en Emir Sader (comp.), El ajuste estructural 
en América Latina. Costos sociales y alternativas, Consejo Latinoamericano de Ciencias Sociales-Clacso, Buenos Aires, pp. 42-53.

García-Moritán, Matilde (1997), Campo verde, un proyecto urbano basado en la auto-organización, un sueño hecho realidad, FHycs-UnjuCentro de Investigaciones sobre Cultura y Naturaleza Andinas, San Salvador de Jujuy.

García-Vargas, Alejandra (2003), "La iconicidad como estrategia metodológica: mapas y planos de San Salvador de Jujuy", Signos y pensamiento, XXII (43), departamento de Comunicación de la Pontificia Universidad Javeriana, Bogotá, pp. 153-162.

García-Vargas, Alejandra (2009), "La desigualdad a la vuelta de la esquina. Los 90 en San Salvador de Jujuy", en Marcelo Lagos (comp.), Jujuy bajo el signo neoliberal. Politica, economía y cultura en la década de los noventa, Ediunju, San Salvador de Jujuy, pp. 357-399.

Gasparini, Leonardo (2006), Monitoring the socio-economic conditions in Argentina, Centro de Estudios Distributivos, Laborales y SocialesDepartamento de Economía-Facultad de Ciencias EconómicasUniversidad Nacional de La Plata, www.depeco.econo.unlp.edu. ar/cedlas, 14 de noviembre de 2009.

Gobierno de la Provincia de Jujuy (1987), Programa de expansión urbana de San Salvador de Jujuy, Proyecto Alto Comedero, Plan Municipal de emergencia, San Salvador de Jujuy.

Gobierno de la Provincia de Jujuy (2005), 2003-2007 El nuevo mandato. Gestión 2004, Secretaría General de la Gobernación-Dirección Provincial de Prensa y Difusión-Gobierno de Jujuy, San Salvador de Jujuy.

Golovanevsky, Laura (2002), "Informalidad, pobreza y exclusión social en Jujuy en los noventa. Empleo informal y precariedad laboral en el Aglomerado San Salvador de Jujuy-Palpalá”, tesis para obtener el grado de magister en teoría y metodología de las ciencias sociales, Facultad de Humanidades y Ciencias Sociales, Universidad Nacional de Jujuy, San Salvador de Jujuy. 
Golovanevsky, Laura (2008), Vulnerabilidad y transmisión intergeneracional de la pobreza. Un abordaje cuantitativo para Argentina en el siglo XXI, Facultad de Ciencias Económicas-UBA-colección de tesis doctorales, Buenos Aires.

Greenstein, Rosalind, Francisco Sabatini y Martim Smolka (2000), "Segregación espacial urbana: fuerzas, consecuencias y respuestas normativas", en Land Lines, 12 (6), Lincoln Institute of Land Policies, Cambridge, pp. 7-9.

INDEC (Instituto Nacional de Estadísticas y Censos) (2001), Censo Nacional de Población, Hogares y Vivienda, Instituto Nacional de Estadísticas y Censos, Buenos Aires.

Janoschka, Michael (2005), "De ciudades dispersas a ciudades perforadas. Una nueva fase de transición demográfica y sus consecuencias morfológicas", en Carlos de Mattos, Oscar Figueroa, Rafael Giménez, Arturo Orellana y Gloria Yáńez (eds.), Gobernanza, competitividad y redes: La gestión en las ciudades del siglo XXI, EURE Libros-Lom Editores, Santiago de Chile, pp. 151-172.

Kanitscheider, Sigrun (2007), "Diferenciación socioespacial en la periferia argentina, el ejemplo de San Salvador de Jujuy", Revista de Geografia del Norte Grande http://dx.dot.org/10.4067/5071834 022007000100002, 23 de octubre de 2009.

Katzman, Rubén (2001), "Seducidos y abandonados: el aislamiento social de los pobres urbanos", Revista de la CEPAL, núm. 75, CepaL, Santiago de Chile, pp. 171-190.

Katzman, Rubén, Fernando Filgueira y Fernando Errandonea (2005), "La ciudad fragmentada. Respuestas de los sectores populares urbanos a las transformaciones del mercado y del territorio en Montevideo", en Alejandro Portes, Bryan Roberts y Alejandro Grimson (eds.), Ciudades latinoamericanas. Un análisis comparativo en el umbral del nuevo siglo, Prometeo Libros, Buenos Aires, pp. 441-507.

Kessler, Gabriel (2008), "Las transformaciones en el delito juvenil en Argentina y su interpelación a las políticas públicas", en Bárbara Potthast, Juliana Ströbele-Gregor y Dörte Wollrad (eds.) Ciuda- 
dania vivida, (in)seguridades e interculturalidad, FEs-Adlaf-Nueva Sociedad, Buenos Aires, pp. 231-245.

Kumar-Bose, Nirmal ([1965]1982), "Calcuta, metrópoli prematura”, en Gerard Piel (ed.), La ciudad. Scientific American, Alianza Editorial, Madrid, pp. 77-96.

Lagos, Marcelo y Mirta Gutiérrez (2006), "Dictadura, democracia y políticas neoliberales. 1976-1999”, en Ana Teruel y Marcelo Lagos (dirs.), Jujuy en la historia. De la colonia al siglo XX, UNIHRFHycs/EdiUnju, San Salvador de Jujuy, pp. 241-294.

Lefebvre, Henri (1972), La revolución urbana, Alianza Editorial, Buenos Aires.

Link, Felipe (2008), "Consideraciones en torno a los conceptos de segregación y fragmentación en los estudios urbanos", web.observatoriodasmetropoles.net, 10 de julio de 2009.

Malizia, Matilde y Pablo Paolasso (2007), "Las nuevas formas de expansión urbana en Yerba Buena (Gran San Miguel de Tucumán, Argentina). Barrios privados, countries y urbanizaciones cerradas", Actas Coloquio Internacional de Neocritica, Universidade Federal do Rio Grande do Sul, Rio Grande do Sul, www.ub.es/ geocrit/9porto/paolasso.htm, 12 de noviembre de 2009.

Marshall, Adriana (1988), Politicas sociales: el modelo neoliberal, Editorial Legasa, Buenos Aires.

Mattos, Carlos A. de (2006), "Modernización capitalista y transformación metropolitana en América Latina: cinco tendencias constitutivas", en Amalia Inés Geraiges de Lemos, Mónica Arroyo y María Laura Silveira (eds.), América Latina: cidade, campo e turismo, ClacsoUniversidad de San Pablo, Buenos Aires, pp. 41-73.

Mertins, Günter (1995), "La diferenciación socio-espacial y funcional de ciudades latinoamericanas: ejemplos del noroeste argentino", Actas I Congreso Investigación social. Región y Sociedad en Latinoamérica, Universidad Nacional de Tucumán, San Miguel de Tucumán, pp. 492-499. 
Michelini, Juan José y Carina, Davies (2009), "Ciudades intermedias y desarrollo territorial: Un análisis exploratorio del caso argentino”, documentos de trabajo GEDEUR, núm. 5, Grupo de Estudios sobre Desarrollo Urbano, Madrid, pp. 1-26.

Mignone, Aníbal (2005), "La movilidad territorial desde la perspectiva de los asentamientos espontáneos en el Gran Resistencia a principios del siglo xxI”, Actas VII Jornadas Argentinas de Estudios de Población, Aepa, Tafí de Valle, Tucuman, pp. 315-328.

Natera Rivas, Juan J. (1998), Urbanización de la pobreza. Procesos migratorios y formación de periferias de invasión en una ciudad intermedia argentina, Universidad de Málaga, Málaga.

Olivera, Adriana (2005), "Transformaciones de una ciudad de escala intermedia en el marco de la globalización. El caso de Mar del Plata”, Actas XI Seminario de Arquitectura Latinoamericana, Universidad Autónoma Métropolitana, septiembre, Oaxtepec.

Portes, Alejandro y Bryan Roberts (2005), "La ciudad bajo el libre mercado. La urbanización de América Latina durante los años de experimentación neoliberal”, en Alejandro Portes, Bryan Roberts y Alejandro Grimson (eds.), Ciudades latinoamericanas. Un análisis comparativo en el umbral del nuevo siglo, Prometeo Libros, Buenos Aires, pp. 19-74.

Prévôt-Schapira, Marie-France (2002), "Buenos Aires en los años 90: metropolización y desigualdades”, Revista EURE, XXVIII (85), Pontificia Universidad Católica de Chile, Santiago de Chile, pp. 31-50.

Ratier, Hugo (1985), Villeros y villas miserias, Centro Editor de América Latina, Buenos Aires.

Reboratti, Carlos (1995), "Migraciones y mercado de trabajo en la Argentina”, en Adolfo Canitrot, Rodolfo Díaz, Alfredo Monza, Juan Luis Bour, Adrián Goldin, María Antonia Gallart, El libro blanco sobre el empleo en la Argentina, MTss, Buenos Aires, pp. 199-220.

Reguillo, Rossana (1995), "Pensar la ciudad desde la comunicación. Un ejercicio necesario”, en Jesús Galindo y Carlos Luna (coords.), 
Campo académico de la comunicación: hacia una reconstrucción reflexiva, ITEso-Conaculta, México, pp. 109-132.

Roberts, Bryan y Alejandro, Portes (2005), “Conclusión. Enfrentando la ciudad del libre mercado", en Alejandro Portes, Bryan Roberts y Alejandro Grimson (eds.), Ciudades latinoamericanas. Un análisis comparativo en el umbral del nuevo siglo, Prometeo Libros, Buenos Aires, pp. 509-556.

Rodríguez, Camilo y Jorge Arriagada (2004), "Segregación residencial en la ciudad latinoamericana”, Revista EURE, xxx (89), Pontificia Universidad Católica de Chile, Santiago de Chile, pp. 5-24.

Romero, José Luis (2001), Latinoamérica. Las ciudades y las ideas, Siglo XXI, Buenos Aires.

Rutledge, Ian (1987), Cambio agrario e integración. El desarrollo del capitalismo en Jujuy: 1550-1960, Serie Monográfica-Proyecto ECIRACicso, San Miguel de Tucumán.

Sabatini, Francisco, Gonzalo Cáceres y Jorge Cerda (2001), "Segregación residencial en las principales ciudades chilenas: Tendencias de las tres últimas décadas y posibles cursos de acción”, Revista EURE, XXvir (82), Pontificia Universidad Católica de Chile, Santiago de Chile, pp. 21-42.

Schmidt, Margarita (2004), "Lo urbano como elemento orientador del desarrollo regional. Dinámicas actuales en ciudades argentinas", Actas II Seminário Internacional sobre Desenvolvimento Regional, Universidad de Santa Cruz do Sul, 28 de septiembre-1 de octubre, Santa Cruz do Sul.

Sennett, Richard (2000), La corrosión del carácter. Las consecuencias personales del trabajo en el nuevo capitalismo, Anagrama, Barcelona.

Stiglitz, Joseph (2001), "Prólogo", en Kart Polanyi ([1957] 2001), La gran transformación. Los orígenes politicos y económicos de nuestro tiempo, FCE, Buenos Aires, pp. 9-19.

Stumpo, Giovanni (1992), "Un modelo de crecimiento para pocos. El proceso de desarrollo de Jujuy entre 1960 y 1985", en Alejandro Isla (coord.), Sociedades y articulación en las tierras altas jujeñas, 
crisis terminal de un modelo de desarrollo, MLAL-Gráficas Mundo Color, Buenos Aires, pp. 41-114.

Svampa, Maristella (2001), Los que ganaron. La vida en los countries y en los barrios privados de Buenos Aires, Biblos, Buenos Aires.

Svampa, Maristella (2004), La brecha urbana. Countries y barrios privados, Capital Intelectual, Buenos Aires.

Valdés, Estela (2009), “¿Guetos urbanos?: Una reflexión a partir de la problemática de la segregación residencial", Revista Geográfica Despertando Latitudes, núm. 1, Ediciones Universitarias de Valparaíso-Pontificia Universidad Católica de Valparaíso, Valparaíso, pp. 37-44.

Vapñarsky, César (1994), "Crecimiento urbano diferencial y migraciones en la Argentina: cambios y tendencias desde 1970", Estudios migratorios latinoamericanos, 9 (27), Centro de Estudios Migratorios Latinoamericanos, Buenos Aires, pp. 225-260.

Vapñarsky, César (1995), "Primacía y macrocefalia en la Argentina: la transformación del sistema de asentamiento humano desde 1950", Desarrollo Económico. Revista de Ciencias Sociales, 35 (138), IDES, Buenos Aires, pp. 227-254.

Wacquant, Löic (2001), Parias urbanos. Marginalidad en la ciudad a comienzos del milenio, Ediciones Manantial, Buenos Aires.

Wacquant, Löic (2004), "Las dos caras de un gueto. La construcción de un concepto sociológico", Revista Renglones, núm. 56, ITEso, Guadalajara, pp. 72-80.

Wacquant, Loïc (2007), Los condenados de la ciudad. Gueto, periferia y Estado, Siglo XXI, Buenos Aires.

Recibido: 13 de febrero de 2010.

Reenviado: 4 de julio de 2011.

Aceptado: 2 de septiembre de 2011. 
Liliana Bergesio. Es magister en teoría y metodología de las ciencias sociales y doctoranda en ciencias sociales por la Universidad Nacional de Jujuy, Argentina. Actualmente es docente de la Facultad de Humanidades y Ciencias Sociales, directora de la Unidad de Investigación en Comunicación Cultura y Sociedad y co-directora del Centro de Estudios Territoriales Ambientales y Sociales de la Universidad Nacional de Jujuy. Su línea de investigación actual se encuadra dentro de la antropología sociocultural en cuyo marco dirige y participa en proyectos de investigación sobre pobreza, género, desigualdad social, ambiente y sociedad, diversidad cultural, representaciones sociales y estudios urbanos. Entre sus últimas publicaciones destacan, en coautoría: Industria y Sociedad. La industria manufacturera en Jujuy y Argentina, Ediunju, Jujuy, 386 pp. (2012); Trabajo infantil en basurales de Jujuy, MTEyss-COPRETI-OIT-UNICEF, Buenos Aires, 79 pp. (2012), Bienes culturales, turismo y desarrollo sostenible. Experiencias de España y Argentina, Sevilla, Signatura Ediciones de Andalucía, pp. 77-116 (2010); Construcción social de la ciudad. San Salvador de Jujuy desde el barrio Alto Comedero, Ediunju, Jujuy, 220 pp. (2009).

Laura Golovanevsky. Es doctora en economía por la Universidad de Buenos Aires, Argentina. Actualmente es miembro de la carrera de investigador científico del Conicet (Consejo Nacional de Investigaciones Científicas y Técnicas), docente de grado en la Facultad de Ciencias Económicas, y docente de postgrado en la Facultad de Humanidades y Ciencias Sociales, ambas pertenecientes a la Universidad Nacional de Jujuy, Argentina. Su línea de investigación actual se refiere a temas de empleo, pobreza, desigualdad social y condiciones de vida. Entre sus últimas publicaciones destacan, en coautoría: Industria y Sociedad. La industria manufacturera en Jujuy y Argentina, Ediunju, Jujuy, 386 pp. (2012); "Ferrocarriles y población: una mirada comparativa en Jujuy (1891-1948-1993)", Revista Estudios del ISHiR, 2 (2), Investigaciones Socio Históricas Regionales, Rosario, pp. 39-66 (2012); “Transmisión intergeneracional de la pobreza en la Argentina: una aproximación empírica”, Estudios del Trabajo, núm. 36, Asociación de Especialistas en Estudios del Trabajo (ASET), Buenos Aires, pp. 85-122 (2010); Construccion social de la ciudad. San Salvador de Jujuy desde el barrio Alto Comedero, Ediunju, Jujuy, 220 pp. (2009). 